\title{
Cultural norms, the persistence of tax evasion, and economic growth
}

\author{
Dimitrios Varvarigos ${ }^{1}$
}

\begin{abstract}
I study the effects of tax evasion on economic growth by focusing on the cultural aspects of tax compliance and their effect on the extensive margin of tax evasion. A cultural norm that determines the contemptibility of tax dodging practices links the past incidence of tax evasion with the tax payers' current incentives to conceal sources of income. This dynamic complementarity may lead to multiple equilibria in the evolution of tax evasion. Due to the latter's effect on capital accumulation, this multiplicity may lead economies in divergent development paths, as long as they differ in the initial magnitude of tax evasion. This happens even though economies may be, on the outset, identical in terms of capital stock and structural characteristics, including those that govern tax enforcement.
\end{abstract}

Keywords Tax evasion $\cdot$ Cultural norms $\cdot$ Fiscal policy $\cdot$ Economic growth

JEL Classification E62 $\cdot \mathrm{H} 26 \cdot \mathrm{O} 41 \cdot \mathrm{Z} 10$

Acknowledgements I am grateful to two anonymous referees for their valuable comments and suggestions on an earlier draft. The usual disclaimer applies.

\footnotetext{
${ }^{1}$ Department of Economics, University of Leicester, Astley Clarke Building, University Road, Leicester LE1 7RH, UK.

$\underline{\text { dv33@le.ac.uk }}$

$+44(0) 1162522184$
} 


\section{Introduction}

Taxation is an important economic policy tool. Tax receipts are a major source of revenues through which governments can finance the adoption of policies such as the provision of productivity-enhancing public services and infrastructure, the redistribution of income etc. Nevertheless, this source of revenue relies, to some extent, on the tax payers' self-reporting of their circumstances with regard to income and wealth. Unfortunately, there is a moral hazard problem inherent to this situation: Despite the fact that many people want to enjoy the benefits accruing from public policies such as the ones mentioned above, fewer of them are willing to contribute their fair share towards the cost of their adoption and implementation. Of course, such circumstances point to the problem of tax evasion, i.e., the illegal practice of reducing one's tax obligation by means of concealing sources of income and wealth from the authorities.

The concerns over the problem of tax evasion should not be restricted to moral grounds. On the contrary, its effects can be far more pervasive and impinge on the overall economic environment. Quantifying such effects is not straightforward though, mainly because the clandestine nature of tax evasion makes it difficult to devise precise measures of its magnitude. Despite this fact, over the past few decades a number of researchers have endeavoured to construct and propose reliable estimates that quantify the extent of this problem. ${ }^{1}$ A look at the estimates for tax evasion across Europe, as these are presented by Nam et al. (2001) and Tsakumis et al. (2007), reveals that those countries with the lowest rates of tax compliance (i.e., Greece, Spain, Portugal and Italy) are also among the countries that have experienced the more pronounced and persistent impact from the recent crisis. In a recent interview, the US president Barack Obama cited Greece's notoriously problematic tax collection mechanism - calling it "famously terrible" - as the prime example of the structural inadequacies that have plunged the country to its severe debt crisis and prolonged period of hampered economic performance (in terms of growth rate). ${ }^{2}$ The above are perhaps prima facie evidence that the problem of tax evasion can have a pivotal role in a country's economic woes. Moreover, they may justify the European Commission's objective to promote and intensify the combined efforts in tackling tax evasion, as part of the overall strategy for the achievement of its political and economic priorities for Europe. ${ }^{3}$

The objective of this paper is to identify the forces behind tax evasion persistence, and analyse its implications for economic growth, in an overlapping generations (OLG) model where cultural characteristics affect tax compliance. These characteristics impinge on a tax payer's incentive to engage in tax evasion by determining the non-pecuniary

\footnotetext{
1 See Andreoni et al. (1998), Slemrod and Yitzaki (2002), Slemrod (2007), Alm (2012), and the references therein.

2 http://www.ekathimerini.com/4dcgi/_w_articles_wsite1_1_01/02/2015_546769.

3http:/ / ec.europa.eu/taxation_customs/resources/documents/taxation/company_tax/transparency/com 2015_136_en.pdf.
} 
(i.e., psychic) costs incurred by those whose fraudulent behaviour is exposed - costs that could comprise social stigma, reputation damage, shame etc. What motivates this approach is the fact that the persistently varied estimates of tax compliance across nations are not solely related to the degree of tax enforcement; they are also symptomatic of the deeper cultural and social characteristics of a nation. Indeed, while there can be little objection to the view that tax enforcement policies, such as frequent tax audits and legal sanctions, can reduce the tax payers' incentives to conceal sources of income and wealth from the authorities, the idea that tax compliance also rests on cultural characteristics has also gained momentum among researchers. ${ }^{4}$ Indeed there is a plethora of empirical analyses that offer credence to this view. Grasmick and Scott (1982) used survey data and found that the perception of social stigma had a significant impact on the respondents' intentions to engage in tax evasion. Baldry (1986) presented the results of experiments showing that the moral costs associated with the revelation of tax evasion are important determinants of tax compliance, while Gächter (2007) interpreted experimental evidence as suggestive that, ceteris paribus, the likelihood of someone engaging in tax evasion is higher if he/she believes that others behave similarly - an idea that is also echoed by Frey (1997). Based on their empirical study, Tsakumis et al. (2007) concluded that the characteristics of national culture are significant in explaining international differences in tax evasion. ${ }^{5}$

In this paper I draw on Gordon (1989) by assuming that the psychic costs, affecting those individuals whose tax evasion is exposed, are driven by a culturally induced, dynamic externality. Particularly, the ignominy of being exposed as a tax evader is negatively related to the incidence of tax evasion among individuals of the previous generation. The dynamic process that ensues due to this effect may generate three steady state equilibria, one of which is unstable and acts as a threshold. Consequently, even when the characteristics of tax enforcement are fixed, tax evasion will converge to a long-run equilibrium where its magnitude can be either low or high, depending on whether the economy's pre-existing condition with regard to the number of people who evade their taxes lies below or above the threshold. Given the detrimental impact of tax

\footnotetext{
4 With respect to the optimal degree of tax enforcement, Baldry (1984) showed that the (costly) process of complete prevention of tax evasion is inefficient. Extending this argument, Slemrod and Yitzhaki (1987) argued that the optimal prevention mechanism is the one that equates the marginal social benefit of lower tax evasion to the marginal cost of enforcement activities. Cremer and Gahvari $(1994,1996)$ have derived formal characterisations of optimal audit probabilities.

5 The relevance of social and cultural dimensions as driving forces behind the persistence of tax evasion gains further support once we consider actual policy plans that have been designed and implemented in order to tackle the high prevalence of activities broadly associated with corruption - activities that include tax fraud. A relevant example is certainly the policy strategy by Hong Kong's Independent Commission Against Corruption (ICAC) (Johnston 1999). Since its establishment during the mid-70s, and as part of its overall strategy in eradicating the problem of endemic corruption in Hong Kong, the ICAC instigated an education programme that was applied to all levels, from kindergarten to higher education. The purpose of the scheme was to make the younger generations aware of the injustice and the adverse socio-economic consequences of corruption, thus discouraging their adherence and/or tolerance to such nefarious activities in the future.
} 
evasion on the (endogenous) process of capital accumulation, this multiplicity can pervade the overall economic environment and determine an economy's long-term prospects. Economies that are on the outset identical in terms of structural characteristics, including those characteristics that govern the degree of tax enforcement, and capital stock, may follow divergent development paths as long as they differ in their level of tax compliance. This is because the cultural norm that affects the individuals' incentives towards tax evasion, acts as a propagation mechanism that perpetuates such differences, thus ingraining the society's attitudes towards tax compliance. ${ }^{6}$ The resulting persistence in the magnitude of tax evasion has significant repercussions for the processes of capital formation and economic growth. ${ }^{7}$

Although there are a number of analyses that have addressed the relation between tax evasion and economic growth within the context of dynamic general equilibrium models, their focus, results, and implications are rather different compared to the present analysis. Roubini and Sala-i-Martin (1995) employ a monetary growth model in which tax evasion induces the government to repress the financial sector, as a means of increasing money demand, expanding the inflation tax base and, therefore, covering the shortfall in tax revenues. Consequently, there is a reduction in the growth rate because financial repression impedes the process of capital accumulation. ${ }^{8}$ In the analysis of Chen (2003), tax evasion has a negative effect on growth because it induces the policy maker to increase the tax rate above the one associated with growth maximisation. Nevertheless, his calibration exercise indicates that the quantitative benefits of stronger tax enforcement may be small, unless the elasticity of output with respect to public capital is relatively high. ${ }^{9}$ Both these analyses are based on representative agent frameworks that abscond from the cultural aspects of tax compliance and do not consider the possibility of multiple equilibria. Blackburn et al. (2006) construct an OLG model in which corrupt tax auditors receive bribes from households in order to facilitate

\footnotetext{
${ }^{6}$ An alternative argument to the one that (partially) attributes the degree of tax compliance to cultural characteristics could be related to the ideas of De Soto (1989). According to his view, activities associated with the informal economy may represent rational decisions in response to the impediments imposed by restrictive government regulations. Nevertheless, in the specific context of tax evasion, this argument would be applicable to the issue of corporate tax compliance, as he focuses on entrepreneurial activities that are constrained by restrictive property rights and entry regulations. In any case, even if such arguments apply to the issue of personal income tax evasion, they do not necessarily conflict with arguments that point to the relevance of cultural and social norms for tax compliance - ideas that, as the previously cited literature indicates, find support from the existing evidence.

${ }^{7}$ In a model where the interactions between corrupt politicians and tax evading households generate selffulfilling equilibria, Litina and Palivos (2014) show that the presence of social stigma can actually eliminate equilibrium multiplicity. In their model, the social stigma is proportional to the amount of evaded taxes; it is not affected by the number of individuals who engage in tax dodging practices.

8 Kafkalas et al. (2014) employ a growth model, similar to the one in Roubini and Sala-i-Martin (1995), and show that, in the presence of tax evasion, the welfare maximising tax rate falls short of the growth maximising one. This happens as long as the government is averse to the magnitude of tax evasion which is captured by the wedge between the actual and the effective tax rate.

${ }_{9}^{9}$ For further analysis on the quantitative and business cycle implications of tax evasion in dynamic general equilibrium models, see Busato and Chiarini (2004) and Ciccarone et al. (forthcoming)
} 
them in concealing their tax evasion. They find two-way causal effects between corruption and economic growth, suggesting the possibility of multiple equilibria. When this possibility materialises, it is the current stock of capital, rather than the magnitude of the tax evasion problem, that determines the economy's dynamic path of economic development. Furthermore, they do not account for the social and cultural aspects of tax compliance - in their model, all households will engage in tax evasion, as long as they find a corrupt public official who is willing to help them conceal their tax fraud. ${ }^{10}$ In this respect, the analysis that is conceptually closer to mine is that of Bethencourt and Kunze (2013) since they also incorporate a dynamic cultural externality à la Gordon (1989) in an OLG framework. Nevertheless, the scope and the results of their analysis are quite different. Predominantly, their objective is to examine how the effect of social norms on tax compliance can account for the positive relation between marginal tax rates and tax evasion, the reduction of the tax evasion/GDP ratio over the transition, and the positive effect of GDP per capita on tax compliance. Their model does not generate multiple equilibria in tax evasion and they do not consider the causal effect of tax evasion on capital accumulation, due to the absence of a productive role for public spending, as well as the lack of any effect of tax evasion on saving behaviour. In my model, tax evasion impedes capital accumulation through two distinct effects - the reduction in productivity-enhancing public spending and the reduction in aggregate private saving. It is for this reason that the multiplicity in the dynamics of tax evasion can have persistent effects on the economy's long-term prospects. ${ }^{11}$

The rest of the paper is structured as follows: In Section 2, I outline the economic environment. In Section 3, I analyse the equilibrium characteristics of tax compliance, I introduce the cultural norm that generates dynamics in the incidence of tax evasion, and I derive the conditions under which the model generates equilibrium multiplicity and persistence in tax evasion. Section 4 focuses on capital accumulation and analyses the joint determination of tax evasion and economic development. In Section 5, I present some further analysis, showing that the results can be robust to the use of alternative setups regarding some of the assumptions employed in the model. Section 6 concludes.

\section{The Economy}

Time is measured in discrete intervals that represent periods and are indexed by $t=0,1,2, \ldots$. The economy is populated by a sequence of overlapping generations of individuals who live for three periods - childhood, youth, and maturity. The population mass of each age cohort is constant over time and equal to $n>1$.

\footnotetext{
10 In the analysis of Blackburn et al. (2012) the marginal benefit of income disclosure is decreasing in the degree of financial market imperfections. They conclude that the incidence of tax evasion is higher in economies where the level of financial development is relatively low.

11 Of course, the channels through which norms can affect the process of capital formation are not restricted to tax compliance. See, for example, Canta et al. (2016).
} 
Consider the individuals who are born in period $t$. They are active during the two periods of their adulthood, i.e. their youth (period $t+1$ ) and their maturity (period $t+2$ ), and have preferences over their consumption during maturity, denoted $c_{t+2} \cdot{ }^{12}$ These preferences are represented by a utility function $u_{t+1}=u\left(c_{t+2}\right)$ where $u(0)=0$, $u^{\prime}>0$, and $u^{\prime \prime} \leq 0$. In what follows, I shall be considering the specific functional form

$$
u\left(c_{t+2}\right)=c_{t+2}^{\theta}, \quad 0<\theta \leq 1 .
$$

During their youth they supply labour to firms that produce the economy's final good and, in exchange, they receive the competitive salary $w_{t+1}$ per unit of effective labour. The income of all young individuals is subject to a flat $\operatorname{tax} \varphi \in(0,1)$. They save their disposable labour income so that when they retire, i.e., during their maturity, they can finance their consumption expenditures by using the proceeds from savings.

As a means of introducing the characteristics that will allow some tax payers to make a convincing, but ultimately false, declaration of their income, I follow Blackburn et al. (2006) in assuming that individuals are heterogeneous in their labour endowments. Whereas a fraction $1-x$ of young individuals will be endowed with one unit of effective labour, nature will bestow $1+l(l>0)$ units of effective labour on the remaining fraction $x \in(0,1)$ of individuals. To save on notation, henceforth I normalise $x n=1$ so that $(1-x) n=n-1$. I shall also assume that the endowment of effective labour is private information to each person, rather than being publicly observable.

Output is produced by a unit mass of perfectly competitive firms that combine capital, denoted $K_{t}$, and labour from young individuals, denoted $L_{t}$, in order to produce $Y_{t}$ units of output according to

$$
Y_{t}=A_{t} K_{t}^{a} L_{t}^{1-a}, \quad a \in(0,1),
$$

where the variable $A_{t}$ denotes total factor productivity and $a(1-a)$ is the capital (labour) share of total income. Productivity can be enhanced by the provision of public services and infrastructure, denoted $G_{t} \cdot{ }^{13}$ In order to finance its expenses for the provision of public infrastructure, the government utilises tax revenues on the basis of a continuously balanced budget. Denoting total tax revenues by $\Phi_{t}$, it follows that

$$
G_{t}=\Phi_{t} .
$$

I draw on Barro and Sala-i-Martin (1992) in assuming that the productivitypromoting role for public services and infrastructure is subject to congestion: Productivity increases as long as public spending rises relative to total output. In other

\footnotetext{
12 Allowing a consumption-saving choice during a person's youth will add significant technical complication without changing the main message from my analysis. In fact, this convention has been employed by other authors as a means of simplifying the technical aspects of their analyses (e.g., Azariadis and Smith 1998; Blackburn et al. 2006). Nevertheless, in Section 5.3 I extend the model towards this direction and use examples to show that the qualitative nature of the main results can remain intact.

13 This idea is meant to capture the well-documented benefits from public spending on health, education, transportation etc. (see Barbiero and Cournède 2013).
} 
words, an increase in total output, for given $G_{t}$, will reduce the quality and availability of public infrastructure. Formally, I capture this idea by specifying

$$
A_{t}=\left(A^{\frac{1}{r}}+\frac{G_{t}}{Y_{t}}\right)^{r}, \quad A, r>0 .
$$

As we can see, this is flexible parameterisation so that, in the absence of productivityenhancing government spending, i.e., when $G_{t}=0$, the production technology reduces to the more conventional form with a constant shift factor, i.e., $Y_{t}=A K_{t}^{a} L_{t}^{1-a}{ }^{14}$

Final good producers rent capital from perfectly competitive financial intermediaries. These intermediaries pool the savings that are deposited to them from young individuals and use them as inputs to an investment technology that generates one unit of capital in period $t+1$ for each unit of output deposited in period $t$. Using $S_{t}$ to denote the total amount of deposits that financial intermediaries receive, the preceding discussion implies that ${ }^{15}$

$$
K_{t+1}=S_{t}
$$

\section{Tax Evasion}

Consider an individual who is representative of the $n-1$ ones endowed with one unit of effective labour. This person will earn labour income equal to $w_{t+1}$ and, after paying taxes, will deposit her entire disposable income of $(1-\varphi) w_{t+1}$ to financial intermediaries. Assuming that the gross interest on saving is $r_{t+2}$, she will enjoy utility equal to $\left[r_{t+2}(1-\varphi) w_{t+1}\right]^{\theta}$.

Now let us consider a person who is representative of the unit mass of individuals to whom nature endows $1+l$ units of effective labour. As long as she is honest in reporting her true circumstances, the decision making process is similar to the one I described before. The only difference is that disposable labour income corresponds to $(1-\varphi) w_{t+1}(1+l)$. Therefore, the individual whose income is truthfully declared to authorities will enjoy utility according to

$$
\overline{u_{t+1}}=\left[r_{t+2}(1-\varphi) w_{t+1}(1+l)\right]^{\theta} .
$$

\footnotetext{
14 We can think of various scenarios where the benefits from productive public spending are subject to congestion. For example, a rise in national income can lead to an increase in transportation activities (personal or commercial), thus contributing to increased traffic and congestion on the roads and highways. Another example can apply to the education sector. As income increases, more families can afford the costs for the higher education of their children (e.g., tuition fees, living expenses). The resulting increase in the student population, if not coupled by a corresponding increase in public education spending, can undermine the quality of the services offered by higher education institutions.

15 Note that the model assumes full depreciation of physical capital. In OLG models, the depreciation rate affects the wedge between the marginal product of capital and the interest rate; it does not affect the equation according to which saving/investment is transformed into capital (see Acemoglu 2009). Given that the interest rate will not impinge on the dynamics of tax evasion and capital formation, the assumption of full depreciation is not critical for the model's results. It is adopted purely for reasons of notational simplicity.
} 
Nevertheless, the fact that the individual's endowment of effective labour and, therefore, her income are private information generates a moral hazard problem. Particularly, by masquerading as a person who was endowed with only one unit of effective labour, she can declare only $w_{t+1}$, thus evading taxes on the part of labour income that corresponds to $w_{t+1} l$. Of course, this implies that disposable (after-tax) income is $(1-\varphi) w_{t+1}+w_{t+1} l$. In this case however, by depositing her entire disposable income to financial intermediaries, the individual may undermine the effort to conceal her wrongdoing as the excessive saving (relative to the reported income) may alert the authorities on her misconduct. For this reason, she can access a storage technology in order to save the amount of concealed income. In practical terms, this storage technology may capture the use of offshore bank accounts as a means of concealing income - a well-known and documented practice, sometimes associated with tax evasion and avoidance. ${ }^{16}$ The return to this storage technology is lower compared to what the formal financial sector offers. Particularly, it yields $q_{t+2}<r_{t+2}$ units of output during maturity for each unit of output stored during youth. Consistent with these ideas, in what follows I shall be assuming that

$$
q_{t+2}=\xi r_{t+2},
$$

where $\xi \in(0,1)$.

Note that this assumption is employed purely as a means of guaranteeing that a deposit to the formal financial sector is the most rewarding method of saving income that is truthfully reported. Otherwise, no one would deposit their savings to financial intermediaries, irrespective of whether they evade taxes or not - an outcome that would have made the process of capital formation impossible. However, it is important to emphasise that assuming $\xi \in(0,1)$ has no bearing on the model's results. In fact, Section 5.2 shows that, qualitatively, the main results are robust to a scenario where $\xi>1$. Furthermore, the current assumption is not alien to real world observations. For example, a report by the Independent newspaper concluded that "the offshore advantage has been whittled away... bank subsidiaries have stopped having to pay headline interest rates to compensate for the perception of offshore banking as a relatively risky option. In fact, the savings rates offshore are now if anything lower than those onshore" ${ }^{17}$ It should also be emphasised that the risk an individual undertakes is not associated with the deposit to the alternative storing technology. Instead, the risky activity is the individual's effort to conceal her actual circumstances from the authorities in order to avoid paying part of her overall tax liability. What the storage technology does is to facilitate the individual in obscuring some of the traces that could signal her wrongdoing.

Let us consider a tax evading individual who remains undetected. Given the above, her consumption during maturity is $c_{t+2}=r_{t+2}(1-\varphi) w_{t+1}+\xi r_{t+2} w_{t+1} l$, thus offering utility

16 See Johannesen and Zucman (2014).

${ }^{17}$ www.independent.co.uk/money/spend-save/the-pros-and-cons-of-an-offshore-account 281260.html 


$$
u_{t+1}^{*}=\left[r_{t+2}(1-\varphi+\xi l) w_{t+1}\right]^{\theta} .
$$

Naturally, for tax evasion to be a meaningful option, the utility of an individual who evades taxes, but remains undetected, must exceed the utility that accrues when the person is honest in reporting her actual income. Comparing (6) and (8), it follows that this is the case when $\xi+\varphi>1-$ a condition that is assumed to hold thereafter.

Now, let us consider a tax evading individual who is eventually detected and apprehended for her misdemeanour. In this case, she will be forced to pay the taxes that apply to the income she concealed, augmented by the penalty rate $p>1$. Note that imposing the fine as a multiple of the unpaid tax is the formulation followed by a large number of analyses on the theory of tax evasion (e.g., Srinivasan 1973; Yitzhaki 1974; Pestieau and Possen 1991; Bernasconi 1998; Hashimzade et al. 2014). This assumption is indeed consistent with reality. For example, in their empirical analysis of tax evasion determinants, Pommerehne and Weck-Hannemann (1996) measure the penalty for tax evasion as a multiplicative fine on the amount of unpaid tax. It is also worth mentioning that the subsequent results remain qualitatively identical even under different formulations, such as fines that are multiples of the whole taxable income. In this case, the only change will entail the scaling of the results, not their qualitative characteristics. Things could be slightly different under a penalty structure that entails a fixed fee. In this case, tax evasion would probably be more likely as income increases. Nevertheless, fixed penalties are not consistent with the assumptions used in the existing literature and are not widely observed in reality.

To ensure that this penalty does not impinge on the part of labour income that was declared and taxed, I assume that $p \in\left(1, \frac{1}{\varphi}\right] .18$ Thus, disposable income is $w_{t+1}(1+l)-\varphi w_{t+1}-p \varphi w_{t+1} l$. Note that by virtue of $\xi<1 \Leftrightarrow q_{t+2}<r_{t+2}$, the taxes and penalties on the concealed income will be paid out of the amount that the individual would have otherwise stored, rather than having it deposited to financial intermediaries. Moreover, given the detection and punishment for tax evasion, all remaining after-tax income will be invested to the option that offers the higher return, i.e., it will be deposited to financial intermediaries. It follows that the individual's consumption during maturity is

$$
c_{t+2}=r_{t+2}[1-\varphi+(1-p \varphi) l] w_{t+1},
$$

a level of consumption expenditures that, due to $p>1$, falls short of the one that accrues under tax compliance, i.e., $c_{t+2}=r_{t+2}(1-\varphi) w_{t+1}(1+l)$. Put differently, a person who

\footnotetext{
18 In principle, one could imagine a penalty rate that is prohibitively high so as to eliminate any incentive to evade taxes. Nevertheless, such a scenario would be empirically implausible.
} 
engages in tax evasion, but is eventually apprehended, is strictly worse-off compared to a person who is honest when declaring her income to authorities. ${ }^{19}$

On top of the financial penalty, the individual who is caught having evaded taxes faces an additional cost. This cost is psychic, rather than pecuniary, and captures the direct utility loss due to the social stigma, the reputation damage, the shame, and the distress that could result from the revelation of her transgression. There are many ways one could incorporate this cost in the framework of analysis. In order to facilitate the model's tractability and to avoid making the intuition of its mechanisms impenetrable, I follow Varvarigos and Arsenis (2015) in assuming that this cost is proportional to the individual's utility from consumption. Specifically, a tax evading individual who is eventually apprehended will enjoy utility according to $u_{t+1}^{* *}=\left(1-\psi_{t+1}\right) c_{t+2}^{\theta}$, where $\psi_{t+1} \in(0,1)$ is the term that measures the aforementioned utility cost. For now, I take $\psi_{t+1} \in(0,1)$ as given but later I will delve deeper into its underlying characteristics. Substituting (9) in the utility function, it follows that

$$
u_{t+1}^{* *}=\left(1-\psi_{t+1}\right)\left\{r_{t+2}[1-\varphi+(1-p \varphi) l] w_{t+1}\right\}^{\theta} .
$$

So far, I have described the circumstances that surround the individual, conditional on either remaining undetected or being apprehended for her nefarious practices. Naturally, her ex ante utility will weight these circumstances, depending on the corresponding probability of each outcome's materialisation. To this purpose, I shall assume that, after declaring her income and paying taxes, she will face the possibility of being audited. The process of auditing will reveal that the tax evading individual has not been sincere in the declaration of her actual income. Furthermore, this process will add a source of heterogeneity among the unit mass of individuals who would consider misreporting their true income. Particularly, an individual $i$ faces a probability $\pi_{t+1}(i) \in[0,1]$ of being audited. This probability is uniformly distributed among the unit mass of individuals who will consider misleading the authorities by fabricating their actual circumstances. Its density function is denoted $g\left(\pi_{t+1}(i)\right)$. Here, the heterogeneity is meant to capture the idea that people have varying abilities in circumventing the laws applicable to tax evasion. On the one hand, some may be more vigilant in keeping a low profile that would not alert others on their excessive disposable income, or they may have connections to people in the public administration and bureaucracy, i.e., people that could facilitate them in eluding detection and punishment (Shik 1991; Xin and Pearce 1996). ${ }^{20}$ On the other hand, others may not be as vigilant and make lifestyle choices or follow patterns of behaviour (e.g., boasting) that will leave them more

\footnotetext{
19 If this was not the case, then the problem would become trivial. Every person with the opportunity to make a convincing, but ultimately false, income declaration in order to evade taxes, would find it optimal to do so.

${ }^{20}$ In a related vein, Artavanis et al. (2012) use data from Greece and show that tax evasion is a more widespread practice among professionals from industries that have powerful guilds and the highest representation among Greek MPs.
} 
vulnerable and exposed to detection and eventual punishment. Note that I attach this type of heterogeneity only to those individuals who receive the extra units of efficient labour. This is because those are the people who will contemplate tax evasion in the first place. The individuals who are endowed with only one unit of efficient labour will not evade their taxes. Irrespective of whether they have connections or not, or whether their lifestyle and patterns of behaviour make them more or less vulnerable to auditing is immaterial because they do not engage in tax evasion.

Nevertheless, it is important to note that my scenario is not inconsistent with the possibility of these tax payers being audited as well. To see this consider the case where the average auditing probability in the economy is $\frac{\bar{\delta}}{2}$ where $\bar{\delta} \in(0,1)$. Naturally, this is also the auditing probability faced by those individuals who do not receive more than one units of efficient labour. As for those who do, assume that they are heterogeneous in that the probability of auditing is $\delta_{t+1}(i)=\bar{\delta} \pi_{t+1}(i)$, where $\pi_{t+1}(i)$ is uniformly distributed on $[0,1]$. As a result, the mean value of $\delta_{t+1}(i)$ corresponds to the average auditing probability of the economy, i.e., $\frac{\bar{\delta}}{2}$. Individuals with $\delta_{t+1}(i)<\frac{\bar{\delta}}{2}$ are those whose connections and vigilance helps them in being less likely to be audited, whereas individuals with $\delta_{t+1}(i)>\frac{\bar{\delta}}{2}$ are those with the lack of connections, or the lifestyle choices, or the patterns of behaviour that make them more vulnerable to being apprehended by authorities. What my model does is to consider the case where $\bar{\delta}=1$ in order to minimise notation. Allowing $\bar{\delta} \in(0,1)$ would not change the qualitative nature of the results or the mechanisms behind them; it would just add a (fixed) scale factor to the model's solutions.

Given the above, the expected utility of a person who contemplates tax evasion is $u_{t+1}(i)=\pi_{t+1}(i) u_{t+1}^{* *}+\left(1-\pi_{t+1}(i)\right) u_{t+1}^{*}$ or, after substituting (8) and (10),

$$
u_{t+1}(i)=\left(r_{t+2} w_{t+1}\right)^{\theta}\left\{\pi_{t+1}(i)\left(1-\psi_{t+1}\right)[1-\varphi+(1-p \varphi) l]^{\theta}+\left(1-\pi_{t+1}(i)\right)(1-\varphi+\xi l)^{\theta}\right\} .
$$

Naturally, the individual will decide to make a false declaration of her income, thus evading part of her tax liability, as long as the expected utility from doing so exceeds the utility that she will enjoy if she is honest about her actual income. The marginal individual is the one who is indifferent between the two options, i.e., the person for whom $u_{t+1}(i)=\overline{u_{t+1}}$. Let $\sigma, h$ and $\eta$ be composite parameter terms given by

$$
\begin{gathered}
\sigma \equiv(1-\varphi+\xi l)^{\theta}, \\
h \equiv[1-\varphi+(1-p \varphi) l]^{\theta},
\end{gathered}
$$

and

$$
\eta \equiv[(1-\varphi)(1+l)]^{\theta},
$$


respectively. Given (12)-(14), we can establish that $\sigma>\eta>h$. It follows that $u_{t+1}(i)=\overline{u_{t+1}}$ defines a critical value

$$
\hat{\pi}_{t+1} \equiv \frac{\sigma-\eta}{\sigma-\left(1-\psi_{t+1}\right) h},
$$

so that individuals for whom $\pi_{t+1}(i) \leq \hat{\pi}_{t+1}$ will engage in tax evasion, whereas individuals for whom $\pi_{t+1}(i)>\hat{\pi}_{t+1}$ will honour their tax obligation. Defining $e_{t+1}$ as the measure of those who decide to reduce their tax liability by fraudulent means, and since $\pi_{t+1}(i)$ is uniformly distributed on $[0,1]$, we have $e_{t+1}=\int_{0}^{\hat{t}_{t+1}} g\left(\pi_{t+1}(i)\right) d \pi_{t+1}(i)$, i.e.,

$$
e_{t+1}=\hat{\pi}_{t+1} .
$$

At this point it should be emphasised that, similar to papers that take the portfolio choice approach on an individual's decision to engage in tax evasion (e.g., Allingham and Sandmo 1972; Bernasconi 1998), the return (in terms of utility) to evading taxes depends on many factors - not only on the parameter $\xi$. Considering all these factors, those who decide to evade their taxes do so exactly because the combination of all these factors lead to a (utility) return that is higher compared to the one resulting under the full declaration of their income. Of course, the difference of my model, in comparison to papers on the portfolio approach, is that, rather than choosing what part of their total income to declare, individuals make a discrete choice on whether or not to declare the part of their income that is not publicly observable.

The results in (15) and (16) elucidate the characteristics that determine the magnitude of tax evasion, as this is measured by the total number of individuals who will ultimately engage in such wrongdoing. Given these, it is straightforward to establish the result that is formally presented in

Proposition 1. The number of individuals who will engage in tax evasion increases when:

$i$. the $p s y c h i c$ cost that they incur if they are eventually exposed, i.e., $\psi_{t+1}$, decreases;

ii. the penalty rate $p$ decreases;

iii. the gap between the returns of formal saving and storage decreases, i.e., if $\xi$ increases;

iv. the degree of risk aversion falls, i.e., if $\theta$ increases.

Proof. See the Appendix

The mechanisms behind these results are straightforward. The direct utility cost $\left(\psi_{t+1}\right)$ that is borne by those who are revealed as having unlawfully avoided part of their tax liability, increases the overall expected costs of such misconduct, thus hindering the incentive to engage in tax evasion. The penalty rate $(p)$ applied to the concealed income increases the expected cost of tax evasion, whereas an increase in the gap between the returns of formal saving and storage (i.e., a lower $\xi$ ) increases the opportunity cost of 
not depositing the hidden income to financial intermediaries - both effects induce fewer individuals to engage in tax evasion. Finally, individuals who are more risk averse (i.e., those with lower $\theta$ ) will be less inclined to opt for the uncertain outcome associated with their effort to evade taxes.

In terms of the tax rate, note that there are two conflicting effects of a higher $\varphi$ on tax evasion. On the one hand, it increases the individual's cost of declaring her income truthfully. On the other hand, given the presence of the penalty rate $p$, it also increases disproportionally the expected pecuniary costs associated with tax evasion. ${ }^{21}$ This is because, in the event that the individual is caught, the effective tax rate on the nondeclared income is $p \varphi$, where $p>1$, as opposed to $\varphi$ which is the rate that the individual would have paid, had she declared her income truthfully in the first place. For the specific case where $\theta=1$, the results in (12)-(16) indicate that

$$
e_{t+1}=\frac{l(\xi+\varphi-1)}{1-\varphi+\xi l-\left(1-\psi_{t+1}\right)[1-\varphi+(1-p \varphi) l]} .
$$

Taking the derivative $\frac{\partial e_{t+1}}{\partial \varphi}$, it is straightforward to establish that its sign depends on the sign of the expression

$$
\psi_{t+1}(1-\varphi)+\xi l-\left(1-\psi_{t+1}\right)(1-p \varphi) l+(\xi+\varphi-1)\left[\psi_{t+1}-\left(1-\psi_{t+1}\right) p l\right],
$$

which is unambiguously positive given that it can be rearranged to yield

$$
\psi_{t+1}[1-\varphi+(1-p \varphi) l+(\xi+\varphi-1)(1+p l)]+l(p-1)(1-\xi)>0,
$$

meaning that in this case the former (positive) effect dominates. However, the two conflicting effects to which I alluded earlier make it difficult to sign $\frac{\partial e_{t+1}}{\partial \varphi}$ analytically for $\theta \in(0,1)$. Nevertheless, numerical simulations indicate that the relation remains positive even for a wider range of values for $\theta$. In Figures 1a-1f, I present three dimensional plots of $e_{t+1}$ against $\varphi \in(0,1)$ and $\psi_{t+1} \in(0,1)$ for three different scenarios regarding the degree of risk aversion, i.e., $\theta=0.3, \theta=0.55$ and $\theta=0.9$. In all cases, I have set $l=1$ and I have allowed $\xi$ and $p$ to vary according to $\xi \in(1-\varphi, 1)$ and $p \in(1,1 / \varphi]$. As we can see, the number of individuals who engage in tax evasion increases as the tax rate becomes higher - an outcome that is consistent with existing evidence (e.g., Clotfelter 1983).

\footnotetext{
21 Assuming that the financial penalty is proportional to the amount of evaded taxes, Yitzhaki (1974) indicated a puzzling result with the portfolio choice approach, i.e., that tax evasion decreases with higher marginal tax rates. Another puzzle that researchers have pointed out with this approach is that, in reality, many individuals abide by the tax regulations, even though the expected (financial) return to tax evasion is positive. Bernasconi (1998) provided a solution to this puzzle based on the idea of different orders of risk aversion.
} 


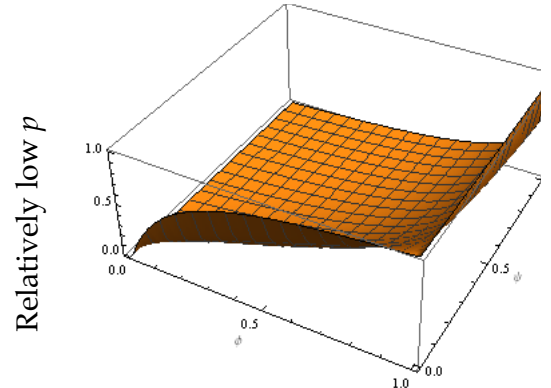

Fig. 1a. $\theta=0.3$

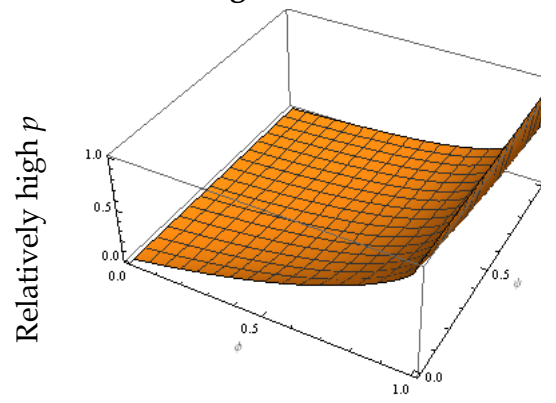

Fig. 1d. $\theta=0.3$

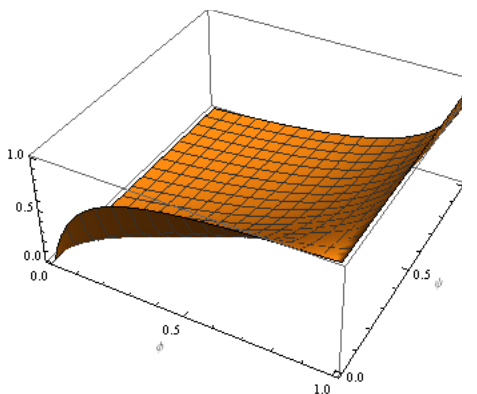

Fig. 1b. $\theta=0.55$

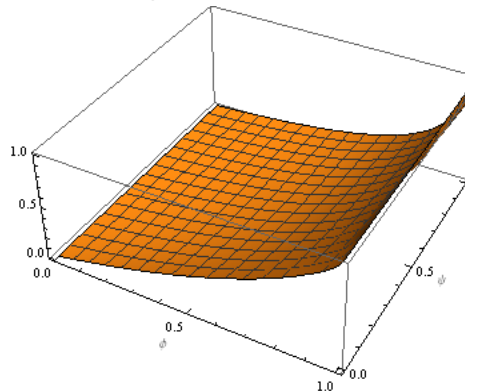

Fig. 1e. $\theta=0.55$

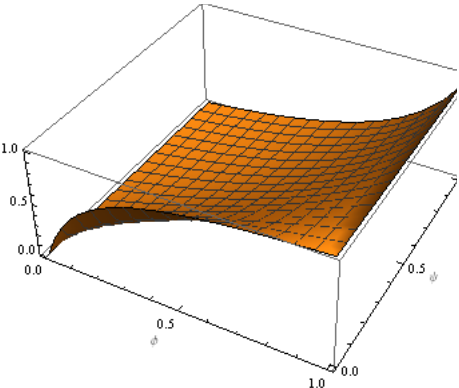

Fig. 1c. $\theta=0.9$

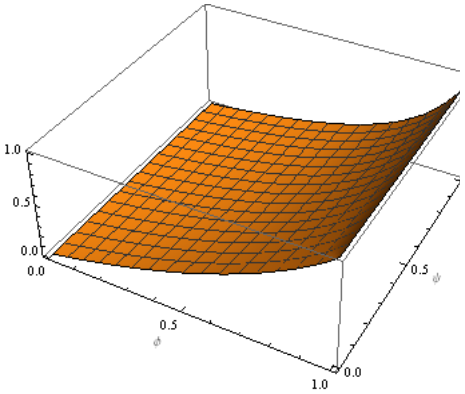

Fig. 1f. $\theta=0.9$

The result in Proposition 1 reveals that the psychic cost (e.g., social stigma; shame; reputation damage etc.) from the revelation of a person's wrongdoing is an important factor in determining the extent of tax compliance. In this part of the analysis, the term $\psi_{t+1}$ will become a focal point: By endogenising its characteristics, I shall develop a framework where the incidence of tax evasion will be inherently dynamic due to the presence of intergenerational externalities in the determination of cultural values and moral codes.

The scenario I postulate is one where each person's personality traits (i.e., attitudes; values; moral codes etc.) are built during childhood. In shaping these characteristics, the overall social environment and the relevant cultural norms play an important role. In the context of this model, the attitudes towards the issue of tax evasion will depend on how prevalent such behaviour is at the time when each person forms the set of her personality characteristics, i.e., during her childhood. Indeed, one would presume that tax evasion would be a less contemptible practice if, at the time they form the set of attitudes and moral codes, individuals are exposed to an environment where more people adhere to this practice. Accordingly, during their adulthood, these individuals will be less susceptible to the ignominy of being exposed as having sought to mislead authorities in order to dodge their tax liability. These ideas are not mere theoretical conjectures. On the contrary, there is evidence in support of such behavioural traits. For example, Barr and Serra (2010) employed university students in a bribery experiment and found that those who grew up in countries where the level of corruption is high were more likely to engage in bribery. The conclusion, in their own words, was that 
"social norms, values and beliefs internalized during childhood may play a determining role in individuals' decisions...later in life" (Barr and Serra 2010, p. 863).22

I capture the aforementioned ideas by following Gordon (1989) and assuming that the psychological factor $\psi_{t+1}$ is negatively related to the number of individuals who engaged in tax evasion during the previous period. ${ }^{23}$ Formally,

$$
\psi_{t+1}=\Psi\left(e_{t}\right),
$$

where $\Psi^{\prime}\left(e_{t}\right)<0, \Psi(0)=m$ and $\Psi(1)=z$ such that $0<z<m<1 .{ }^{24}$ Substituting (15) and (17) in (16) yields

$$
e_{t+1}=\frac{\sigma-\eta}{\sigma-\left[1-\Psi\left(e_{t}\right)\right] h} \equiv F\left(e_{t}\right),
$$

an expression that elucidates the point that was made earlier. Specifically, the intergenerational nature of the cultural externality that I posited through the expression in (17) is an underlying source of dynamics in the incidence of tax evasion among individuals.

Let us examine whether there are steady state solutions $e_{t+1}=e_{t}=\hat{e}$ to which the incidence of tax evasion will converge in the long-run. Using (18), it is straightforward to establish that

$$
F^{\prime}\left(e_{t}\right)=-\frac{(\sigma-\eta) h \Psi^{\prime}\left(e_{t}\right)}{\left\{\sigma-\left[1-\Psi\left(e_{t}\right)\right] h\right\}^{2}}>0,
$$

and

$$
\begin{aligned}
& F(0)=\frac{\sigma-\eta}{\sigma-(1-m) h} \equiv \underline{f}, \\
& F(1)=\frac{\sigma-\eta}{\sigma-(1-z) h} \equiv \bar{f},
\end{aligned}
$$

where $0<\underline{f}<\bar{f}<1$. The analysis in (19)-(21) reveals that there is at least one $\hat{e} \in(0,1)$ such that $\hat{e}=F(\hat{e})$, where $F^{\prime}(\hat{e}) \in(0,1)$, i.e., a stable steady state equilibrium. I write "at least" because, at the moment, there is nothing to preclude the possibility of multiple stationary points. In order to examine this possibility, I shall begin by defining the function

$$
B(e)=\frac{e}{F(e)}=\frac{e\{\sigma-[1-\Psi(e)] h\}}{\sigma-\eta},
$$

where $B(0)=0$ and $B(1)=\bar{f}^{-1}>1$. Given (18), a steady state is any solution $\hat{e} \in(0,1)$ for which $B(\hat{e})=1$. Taking the derivative of $B(e)$ yields

22 Similar implications for the issue of corporate tax evasion emerge in the study of DeBacker et al. (2015).

${ }^{23}$ A similar idea, but in a static context, has been employed by Kim (2003) in a model of tax evasion and income inequality.

24 During the initial period $t=0$, there is a given $\Psi_{0}$ that implicitly defines an initial value $e_{-1}$. This can represent the number of the initial old individuals that do not nurture the young with the view that tax evasion is a contemptible enough practice. 


$$
B^{\prime}(e)=\frac{\sigma-h+h\left[\Psi(e)+e \Psi^{\prime}(e)\right]}{\sigma-\eta} .
$$

In order to facilitate the tractability of the subsequent analysis, I shall employ a specific functional form for the direct utility cost incurred by individuals who have been apprehended for evading their taxes. Henceforth, the function $\psi_{t+1}=\Psi\left(e_{t}\right)$ will take the form

$$
\Psi\left(e_{t}\right)=\frac{m \kappa}{\kappa+v e_{t}^{\beta}},
$$

where $\kappa, v>0$ and $\beta>1$. Notice that in this case, the term $\Psi(1)=z$ corresponds to the composite parameter term $z \equiv \frac{m \kappa}{\kappa+v}$. Given (24), the term $\Psi(e)+e \Psi^{\prime}(e)$ can be written as

$$
\frac{m \kappa}{\kappa+v e^{\beta}}-\frac{m \kappa \beta v e^{\beta}}{\left(\kappa+v e^{\beta}\right)^{2}}
$$

which can be substituted back in (23), resulting in

$$
B^{\prime}(e)=\frac{\sigma-h+\frac{h m \kappa}{\kappa+v e^{\beta}}-\frac{h m \kappa \beta v e^{\beta}}{\left(\kappa+v e^{\beta}\right)^{2}}}{\sigma-\eta} .
$$

Next, I shall define the composite terms

$$
\begin{gathered}
\mu \equiv \frac{h m(\beta-1)}{2(\sigma-h)}-1, \\
\delta \equiv \frac{h m}{\sigma-h}+1,
\end{gathered}
$$

and assume that $\kappa$ is sufficiently low, or $v$ is sufficiently high, in order for the following condition to hold:

Assumption 1. Whenever $\mu^{2}-\delta>0 \Leftrightarrow \frac{(\beta-1)^{2}}{\beta}>\frac{4(\sigma-h)}{h m}$ then $\frac{\kappa}{v}\left(\mu+\sqrt{\mu^{2}-\delta}\right)<1$.

The reason for employing this assumption will become clear shortly, while discussing the intuition behind the results that can be extracted from the dynamics of tax evasion (see Propositions 2 and 3 later). For now, we can return to Eq. (26) and derive the detailed characteristics of the function $B(e)$ by virtue of

Lemma 1. If $\mu^{2}<\delta$ then $B^{\prime}(e)>0 \forall e$. If $\mu^{2}>\delta$ then there exist $e^{*}$ and $e^{* *}\left(0<e^{*}<e^{* *}<1\right)$ such that

$$
B^{\prime}(e)\left\{\begin{array}{clc}
>0 & \text { if } & e<e^{*} \\
<0 & \text { if } & e^{*}<e<e^{* *} . \\
>0 & \text { if } & e>e^{* *}
\end{array}\right.
$$


Proof. See the Appendix. ${ }^{25}$

Using the result in Lemma 1 we can determine all the possible outcomes concerning the steady state equilibrium associated with (18). These outcomes are presented formally in the following Propositions:

Proposition 2. There is a unique steady state equilibrium $\hat{e}$ for the number of individuals who engage in tax evasion, if:
i. $\mu^{2}<\delta$, or
ii. $\mu^{2}>\delta$, and either $B\left(e^{*}\right)<1$ or $B\left(e^{* *}\right)>1$.

This equilibrium is asymptotically stable.

Proposition 3. There are three steady state equilibria $\hat{e}_{l}, \hat{e}_{m}$, and $\hat{e}_{h}\left(\hat{e}_{l}<\hat{e}_{m}<\hat{e}_{h}\right)$ for the number of individuals who engage in tax evasion, if $\mu^{2}>\delta, B\left(e^{*}\right)>1$, and $B\left(e^{* *}\right)<1$. Two of these equilibria, $\hat{e}_{l}$ and $\hat{e}_{h}$, are locally asymptotically stable whereas $\hat{e}_{m}$ is unstable.

Proofs. See the Appendix.

The result in Proposition 2 is indicative of a situation where the dynamics of tax evasion generate a unique steady state equilibrium, like the one illustrated on the phase diagram of Figure 2. No matter what the existing conditions regarding the incidence of tax evasion are, in the long-run this will converge to $\hat{e}$. Current imbalances in the magnitude of tax evasion among different economies will eventually wane, insofar as these economies are structurally similar.

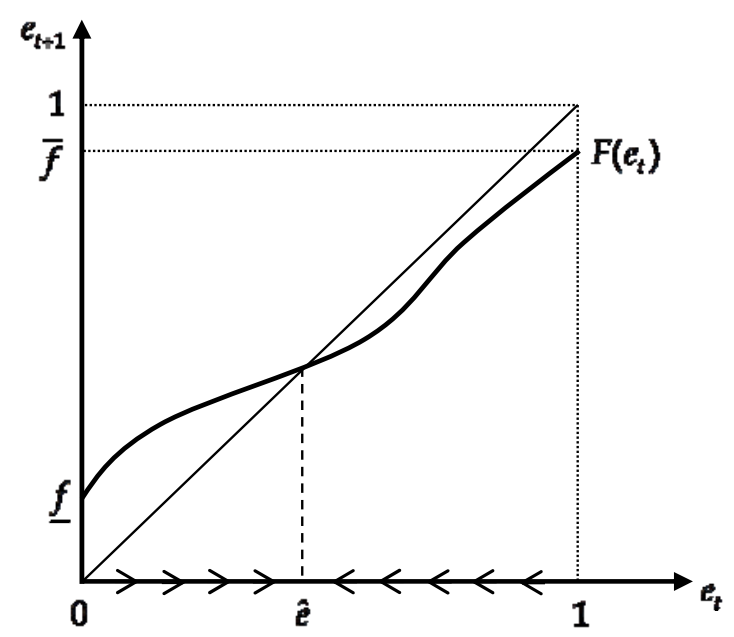

Fig. 2. Unique steady state equilibrium

25 The Appendix provides explicit solutions for $e^{*}$ and $e^{* *}$. 
The more interesting situation emerges in Proposition 3 and illustrated in Figure 3. In this case, the multiplicity of equilibria in the magnitude of tax evasion, as well as the underlying intuition, echo the influential paper of Cooper and John (1988). The condition underlying Assumption 1 corresponds to the necessary condition for multiplicity in Cooper and John (1988), i.e., the condition ensuring that, at some point in the domain of $e_{t}$, the slope of the transition graph is exactly equal to unity. In other words, there exists a point for which a change in tax evasion today, and its effect on the psychic cost faced by the future generation of exposed tax evaders, will lead to a change in tax evasion in the future whose magnitude is at least as equal. ${ }^{26}$ As in Cooper and John (1988) however, this condition is not sufficient to generate multiple equilibria. Another two conditions that ensure this are included in Proposition 3, i.e., $B\left(e^{*}\right)>1$, and $B\left(e^{* *}\right)<1$. These guarantee that there is at least one point satisfying $e_{t+1}=e_{t}=\hat{e}$ for which $F^{\prime}(\hat{e})>1$ - in this case, this unstable steady state corresponds $\hat{e}_{m}$.

With these in mind, the intuition behind the path-dependency of the long-run equilibrium is as follows. The properties of $\hat{e}_{m}$ imply that, around this unstable steady state, future generations will be very responsive to the effects of the current incidence of tax evasion on the psychological factor that is captured by $\psi_{t+1}$. If $e_{t}>\hat{e}_{m}\left(e_{t}<\hat{e}_{m}\right)$ then an increase (decrease) in tax evasion today reduces (increases) the psychic cost $\psi_{t+1}$ by so much that the incidence of tax evasion in the future will increase (decrease) at a higher rate. Hence, the number of tax evading individuals grows (declines) over time until it converges to the stable equilibrium $\hat{e}_{h}\left(\hat{e}_{l}\right)$.

For illustrative purposes, Figure 4 shows the emergence of multiple equilibria in a specific numerical example. Particularly, it plots $B(e)-1$ against $e$ using $\varphi=0.3$, $p=1.25, l=1, \theta=0.3, \xi=0.85, v=800, \kappa=0.9, m=0.95$ and $\beta=3$. As these are numerical values consistent with the conditions outlined in Proposition 3 , we see that there are three solutions for which $B(e)-1=0$. In this specific example, the three steady state equilibria correspond to $\hat{e}_{l}=0.032, \hat{e}_{m}=0.212$, and $\hat{e}_{h}=0.591$.

\footnotetext{
${ }^{26}$ In terms of the function $\Psi\left(e_{t}\right)$, Assumption 1 implies that there is an inflexion point below (above) which the function decreases at an increasing (decreasing) rate. Put differently, the decrease of the psychic cost as a result of increasing tax evasion in the past is less pronounced at relatively high levels of $e_{t}$.
} 


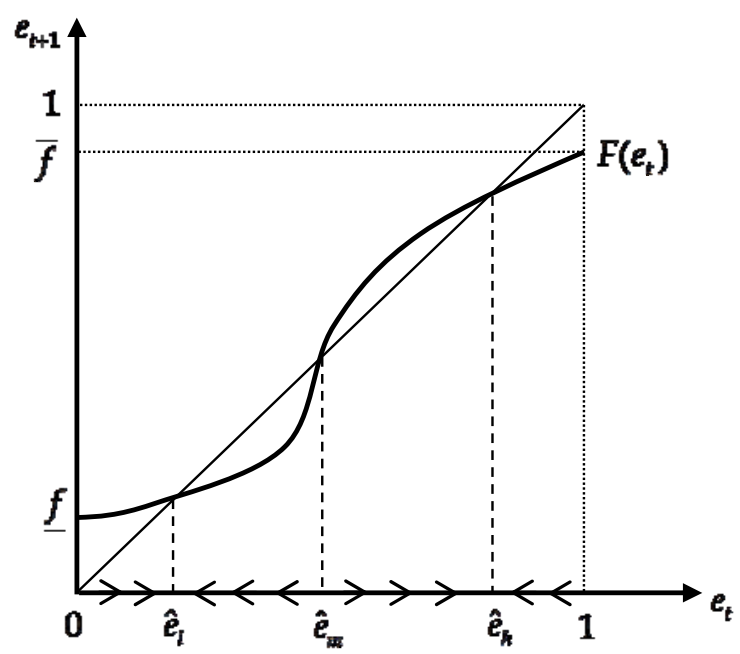

Fig. 3. Multiple steady state equilibria

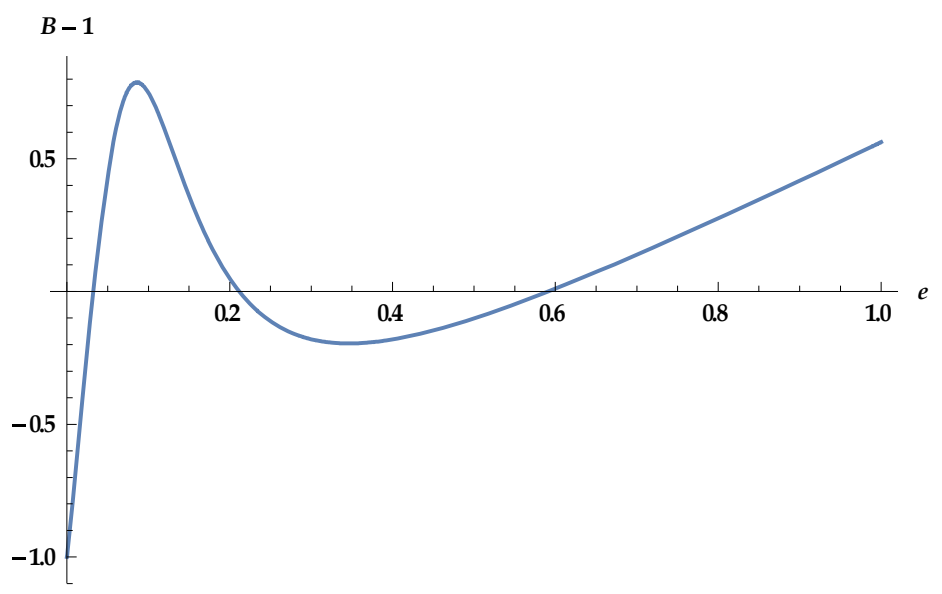

Fig. 4. A numerical example with multiple equilibria

\section{Tax Evasion and the Path of Economic Development}

So far, I have focused on the determinants of tax evasion and its persistence. The overall objective of my analysis is to identify the implications of tax evasion persistence for the economy's growth performance. For this reason, it is important to identify the impact of tax evasion on the process of capital accumulation.

Using the production technology in (2), the wage per unit of effective labour in period $t$ is

$$
w_{t}=(1-a) A_{t} K_{t}^{a} L_{t}^{-a}=(1-a) \frac{Y_{t}}{L_{t}}
$$


i.e., profit maximising firms will offer the wage that corresponds to the marginal product of labour. Let $k_{t}=\frac{K_{t}}{n}$ denote capital per person and note that the equilibrium in the labour market corresponds to $L_{t}=n+l$. Substituting these in (29) yields

$$
w_{t}=(1-a) A_{t} k_{t}^{a}\left(\frac{n}{n+l}\right)^{a} \text {. }
$$

As I indicated earlier, total factor productivity is increasing in the provision of public services and infrastructure - activities that are financed by means of labour income taxation. The aggregate tax revenues in period $t$ comprise the following: Firstly, there is a mass of $n-1$ individuals, each of whom pays $\varphi w_{t}$. Secondly, there is a unit mass of individuals, of whom $1-e_{t}$ declare their actual income and each one pays $\varphi w_{t}(1+l)$. The remaining mass of $e_{t}$ individuals only declare the income corresponding to one unit of effective labour, thus paying $\varphi w_{t}$ each. Nevertheless, each of them faces a probability of being audited, in which case they will pay the tax on the income they concealed, augmented by the applicable financial penalty. All in all, total tax revenues are given by

$$
\Phi_{t}=(n-1) \varphi w_{t}+\left(1-e_{t}\right) \varphi w_{t}(1+l)+e_{t} \varphi w_{t}+p \varphi w_{t} l \int_{0}^{e_{t}} \pi_{i}(t) g\left(\pi_{i}(t)\right) d \pi_{i}(t) .
$$

Substituting (31) in (3), we can eventually express public spending according to ${ }^{27}$

$$
G_{t}=\varphi w_{t}\left[n+l\left(1-e_{t}+p \frac{e_{t}^{2}}{2}\right)\right],
$$

which can be combined with (29) and $L_{t}=n+l$ to rewrite (4) as

$$
A_{t}=\left\{A^{\frac{1}{r}}+\frac{(1-a) \varphi}{n+l}\left[n+l\left(1-e_{t}+p \frac{e_{t}^{2}}{2}\right)\right]\right\}^{r} .
$$

Substituting (33) in (30), it follows that

$$
w_{t}=(1-a)\left(\frac{n}{n+l}\right)^{a}\left\{A^{\frac{1}{r}}+\frac{(1-a) \varphi}{n+l}\left[n+l\left(1-e_{t}+p \frac{e_{t}^{2}}{2}\right)\right]\right\}^{r} k_{t}^{a} .
$$

Now let us determine the components of aggregate saving in period $t$. Those individuals with only one unit of effective labour, of whom there are $n-1$, will deposit an amount of $(1-\varphi) w_{t}$ each. From the unit mass of individuals who are endowed with

\footnotetext{
27 An assumption that is implicit to the framework is that the process of auditing does not absorb resources away from the public budget. The results would remain qualitatively similar, had I assumed that tax enforcement absorbs a fixed fraction of public spending in each period. Alternatively, one could consider the case where public revenues lead to a higher probability of detection. Apart from the insurmountable mathematical complexity of such a scenario - among other things, it would imply that the probability of detection, which is an important determinant of tax evasion, would depend on the magnitude of tax evasion itself - it raises issues of optimal allocation of government spending (i.e., a trade-off between prevention/enforcement and provision of public infrastructure) that go beyond the scope of this analysis. On the current literature's view regarding the cost-benefit considerations of increasing the resources towards tax enforcement, see the discussion on Section 6.
} 
$1+l$ units of effective labour, a fraction $1-e_{t}$ will deposit $(1-\varphi) w_{t}(1+l)$ since they are honest in their income declaration. Each of the remaining $e_{t}$ individuals will declare $w_{t}$ in labour income, therefore they will only deposit $(1-\varphi) w_{t}$ to financial intermediaries. They do so in their attempt to blur the traces of their tax fraud by accessing opportunities that lie outside the domain of the economy's formal financial sector, in order to store their concealed income $w_{t} l$. Nevertheless, some of them will be audited, in which case they will be forced to pay the evaded taxes, augmented by the financial penalty; any residual income will be deposited to financial intermediaries. In short, aggregate saving in period $t$ is given by

$$
\begin{aligned}
S_{t} & =(n-1)(1-\varphi) w_{t}+\left(1-e_{t}\right)(1-\varphi) w_{t}(1+l)+e_{t}(1-\varphi) w_{t} \\
& +(1-p \varphi) w_{t} l \int_{0}^{e_{t}} \pi_{i}(t) g\left(\pi_{i}(t)\right) d \pi_{i}(t)
\end{aligned} .
$$

Combining (5) and (35) gives us

$$
K_{t+1}=(1-\varphi) w_{t}\left[n+l\left(1-e_{t}+\frac{1-p \varphi}{1-\varphi} \frac{e_{t}^{2}}{2}\right)\right],
$$

in which we can substitute (34) and use $k_{t+1}=\frac{K_{t+1}}{n}$ to get

$$
k_{t+1}=v\left[A^{\frac{1}{r}}+\frac{(1-a) \varphi}{n+l} Q_{G}\left(e_{t}\right)\right]^{r} Q_{K}\left(e_{t}\right) k_{t}^{a} \equiv \omega\left(k_{t}, e_{t}\right),
$$

where

$$
\begin{gathered}
v \equiv \frac{(1-\varphi)(1-a)}{n}\left(\frac{n}{n+1}\right)^{a}, \\
Q_{G}\left(e_{t}\right) \equiv n+l\left(1-e_{t}+p \frac{e_{t}^{2}}{2}\right), \\
Q_{K}\left(e_{t}\right) \equiv n+l\left(1-e_{t}+\frac{1-p \varphi}{1-\varphi} \frac{e_{t}^{2}}{2}\right) .
\end{gathered}
$$

The preceding analysis can facilitate us in identifying the impact of $e_{t}$ on the process of capital formation. This is an issue formally analysed through

Proposition 4. An increase in the number of individuals who engage in tax evasion impedes the process of capital accumulation.

Proof. See the Appendix.

There are two distinct effects of tax evasion on the processes of investment and capital formation. On the one hand, it reduces the potential amount of funds available for investment, as tax evading individuals avoid depositing their non-declared income to financial intermediaries in order to obscure any trace that could signal their 
misdemeanour. On the other hand, tax evasion impinges on the provision of productivity-enhancing public infrastructure due to its negative effect on aggregate public revenues. Hence, the incidence of tax evasion has a negative overall effect on the process of capital formation; it is an inhibiting factor to both aggregate private saving/investment and to aggregate productivity.

Now, recall that Propositions 2 and 3 revealed outcomes that are rather different in terms of their dynamic implications. In Proposition 2, I identified conditions under which the magnitude of tax evasion converges to a unique, stable long-run equilibrium, irrespective of the pre-existing conditions regarding such illegal practices by tax payers. Under such circumstances, the implications for economic growth and development are straightforward. Specifically, by alluding to Eq. (37), one can determine a unique stable steady state solution for the stock of capital (and income) per person - a steady state whose value will be determined solely by the structural characteristics that affect both tax evasion and the process of investment and capital accumulation. Conditionally on being structurally similar, economies that differ temporarily in terms of the magnitude of tax evasion will see such imbalances waning as they converge to the long-run equilibrium.

However, the focus of the current analysis is on circumstances under which temporary imbalances in the level of tax compliance may persist in the long-run. Given that such scenarios are consistent with the implications of Proposition 3, in what follows I shall focus my attention to the equilibrium implications that emerge under

Assumption 2. The conditions outlined in Proposition 3, i.e., $\mu^{2}-\delta>0, B\left(e^{*}\right)>1$, and $B\left(e^{* *}\right)<1$, hold.

With this in mind, we can establish the following results on the steady state equilibria of the dynamic system characterised by (37) and (18), their stability properties and, therefore, the long-run equilibrium:

Lemma 2. There are three pairs of steady state equilibria, $\left(\hat{k}_{l}, \hat{e}_{h}\right),\left(\hat{k}_{m}, \hat{e}_{m}\right)$ and $\left(\hat{k}_{h}, \hat{e}_{l}\right)$, where $\hat{k}_{h}>\hat{k}_{m}>\hat{k}_{l}$ and $\hat{e}_{h}>\hat{e}_{m}>\hat{e}_{l}$. Out of these, only the pairs $\left(\hat{k}_{l}, \hat{e}_{h}\right)$ and $\left(\hat{k}_{h}, \hat{e}_{l}\right)$ are locally asymptotically stable.

Proof. See the Appendix.

Proposition 5. The long-run equilibrium of the economy depends on its current conditions with respect to the magnitude of tax evasion. Particularly, the economy will eventually converge to $\left(\hat{k}_{l}, \hat{e}_{h}\right)$ if $e_{t}>\hat{e}_{m}$ or to $\left(\hat{k}_{h}, \hat{e}_{l}\right)$ if $e_{t}<\hat{e}_{m}$.

Proof. It follows from the results in Proposition 3, Proposition 4, and Lemma 2. 
The major implication from Proposition 5 is that the presence of cultural norms in the formation of the society's attitudes with respect to the issue of tax evasion, may act as a propagation mechanism that perpetuates current conditions and establishes them into permanent fixtures of the economy's long-term prospects. In order to delve deeper into the significance of this result, consider two economies that are currently identical in terms of their capital stocks and the structural characteristics that govern preferences, technologies and tax enforcement. Their only difference relates to the magnitude of tax evasion, which is relatively low $\left(e_{t}<\hat{e}_{m}\right)$ in one economy and relatively high $\left(e_{t}>\hat{e}_{m}\right)$ in the other. In the former case, tax evasion will decline over time as successive generations of individuals are nurtured with the view that tax fraud is a contemptible enough practice so as to deter them from adhering to it. As the incidence of tax evasion declines, the process of capital accumulation is stimulated, hence leading the economy into a path of higher economic development. The future prospects of the economy in which the magnitude of tax evasion is currently high will be quite different though. Given the historically low level of tax compliance across the population, tax evasion is not deemed reprehensible enough to deter successive generations of individuals from attempting to conceal some sources of income. As tax evasion increases, it impedes the process of capital formation, thus preventing the economy from sustaining high levels of economic development.

The dynamics of the economy can be illustrated by means of a phase diagram. Given (18), the $\Delta e_{t}=0$ loci are the three vertical lines in Figure 5a, corresponding to the three steady state equilibria derived in Proposition 3. To draw the $\Delta k_{t}=0$ locus we can use Eq. (37) from which $k_{t+1}-k_{t}=0$ defines a function $k_{t}=\Omega\left(e_{t}\right)$ where $\Omega^{\prime}\left(e_{t}\right)<0$ according to the result in Proposition 4 (see Figure 5b). In Figure 6 I combine the $\Delta e_{t}=0$ and $\Delta k_{t}=0$ loci on a phase diagram, from which we can verify the implications of Proposition 5. Ceteris paribus, the current conditions regarding the magnitude of tax evasion, i.e., whether it lies below or above the threshold $\hat{e}_{m}$, determine the long-term prospects of the economy.

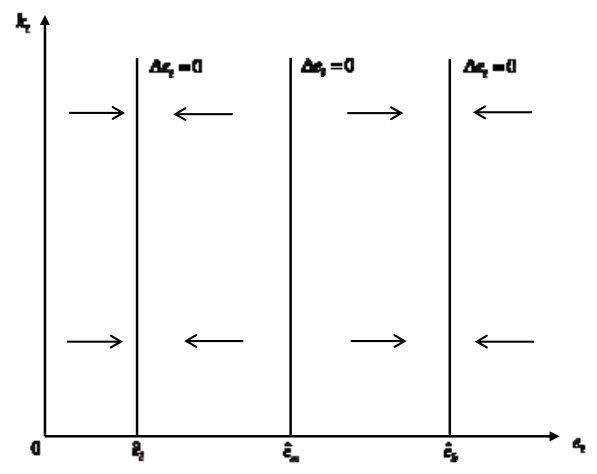

Fig. 5a. $\Delta e_{t}=0$ loci

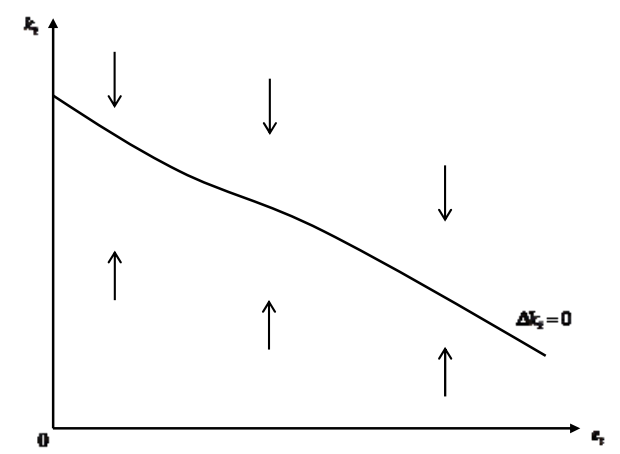

Fig. 5b. $\Delta k_{t}=0$ locus 


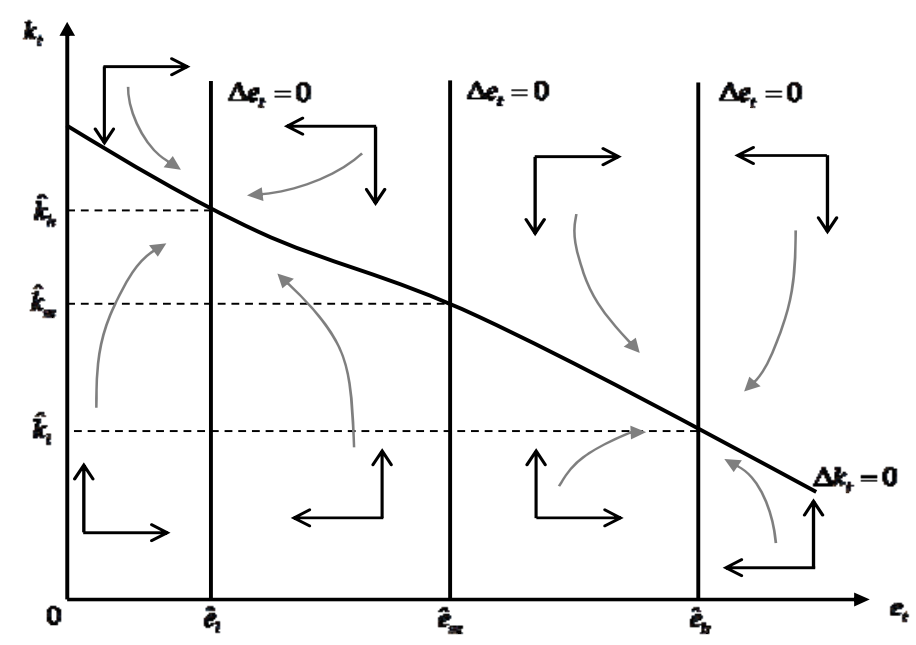

Fig. 6. Phase diagram

Naturally, the characteristics that govern the tax evasion-economic growth nexus in my model have significant policy implications, especially on those aspects of policy making that aim at instituting higher tax compliance within the society. Firstly, they point to the importance of these policy targets, not only with respect to temporary benefits in terms of public revenues, but also as a means of improving the overall longterm prospects of the economy. Secondly, the underlying mechanism that generates persistence in tax evasion implies that an effective policy strategy could complement traditional approaches to tax enforcement (e.g., auditing and legal sanctions) with measures that aim at changing the public's consciousness on the widespread repercussions of nefarious practices such as tax fraud, thus changing their overall tax culture. For example, an appropriate policy could entail a long-term plan through which the education system will inculcate in successive generations of people the idea that tax fraud is a reprehensible practice that has major and widespread negative repercussions, both economic and social. Furthermore, the previous policy suggestion can be complemented by efforts to promote the sense of citizenship and community among the population, thus inducing tax compliance and greater social contemptibility in response to the revelation of one's effort to avoid his/her fair share in the contribution of common goods. The importance of such policies becomes even more obvious once we consider the possibility that budgetary or political constraints may impose insurmountable obstacles against a government's efforts to increase the amount of resources devoted to tax enforcement.

Of course, the characteristics of multiplicity in the determination of tax evasion, as this was shown in Section 3, may also provide a role for more conventional types of fiscal policy. For example, consider a reduction of the marginal tax rate. Given the analysis of Section 3, it is possible that such a policy would shift the $F\left(e_{t}\right)$ curve downwards, implying a decrease in the stable equilibria $\hat{e}_{l}$ and $\hat{e}_{h}$, as well as a 
corresponding increase in the threshold $\hat{e}_{m}$. In fact, it could even be possible to shift $F\left(e_{t}\right)$ sufficiently, so as to establish $\hat{e}_{l}$ as the unique equilibrium. Nevertheless, there are additional dimensions in such a policy recommendation. Firstly, there may be budgetary constraints that restrict the scope for significant reductions in tax rates. Secondly, given that public spending is productive in this framework, a possible side effect of such a policy could be a cost in terms of reduced growth performance.

\section{Alternative Approaches and Extensions}

\subsection{An Alternative Source of Heterogeneity among Potential Tax Evaders}

In the main part of the paper, it was assumed that the source of heterogeneity among individuals with more than one unit of efficient labour (i.e., the individuals who have the opportunity to dodge their tax obligations by misrepresenting their true types) is their ability to avoid detection by authorities. In this section, I shall consider a different form of heterogeneity. Particularly, I shall assume that it is the additional amount of efficient labour that is uniformly distributed on the $[0,1]$ interval. Also note that, for reasons of analytical tractability, the subsequent analysis applies the condition $\theta=1$.

Now, Eq. (6), (8) and (10) change to

$$
\begin{gathered}
\overline{u_{t+1}}=r_{t+2}(1-\varphi) w_{t+1}\left(1+l_{i}\right), \\
u_{t+1}^{*}=r_{t+2}\left(1-\varphi+\xi l_{i}\right) w_{t+1}, \\
u_{t+1}^{* *}=\left(1-\psi_{t+1}\right) r_{t+2}\left[1-\varphi+(1-p \varphi) l_{i}\right] w_{t+1},
\end{gathered}
$$

respectively. Given these, and the (constant) probability $\pi \in(0,1)$ of a tax evader being eventually caught, the condition for which an individual will find optimal to evade some of her tax liability is

$$
\pi\left(1-\psi_{t+1}\right) r_{t+2}\left[1-\varphi+(1-p \varphi) l_{i}\right] w_{t+1}+(1-\pi) r_{t+2}\left(1-\varphi+\xi l_{i}\right) w_{t+1}>r_{t+2}(1-\varphi) w_{t+1}\left(1+l_{i}\right),
$$

from which we can infer a critical value

$$
\hat{l}_{t+1}=\frac{\psi_{t+1} \pi(1-\varphi)}{\pi\left(1-\psi_{t+1}\right)(1-p \varphi)+(1-\pi) \xi-(1-\varphi)} .
$$

Given Eq. (44), individuals with $l_{i} \in\left(\hat{l}_{t+1}, 1\right]$ are those who will engage in tax evasion.

Note that a sufficient condition to ensure $0<\hat{l}_{t+1}<1$ is $\frac{1-\pi}{1+\pi} \xi+\varphi>1$. Substituting (17) in (44), it follows that the number of individuals who evade their taxes is

$$
e_{t+1}=1-\frac{\psi\left(e_{t}\right) \pi(1-\varphi)}{\pi\left[1-\psi\left(e_{t}\right)\right](1-p \varphi)+(1-\pi) \xi-(1-\varphi)}=F\left(e_{t}\right),
$$

where $F^{\prime}\left(e_{t}\right)>0$ by virtue of $\Psi^{\prime}\left(e_{t}\right)<0$.

According to (45), the individuals who evade tax payments are those with the relatively high levels of income, among the ones who have the opportunity to falsify their actual circumstances. The intuition is that the higher income implies a greater potential benefit (in terms of unpaid taxes) from engaging in tax evasion. Note that this 
is a result that finds support from the existing evidence. For example, the empirical analysis of Feinstein (1991) indicates that the likelihood of tax evasion is increasing in the taxpayer's income. As for the dynamics of tax evasion, the results are qualitatively similar to the ones in the original version of the model. Particularly, a higher $e_{t}$ implies that the psychic cost of being revealed as a tax evader is smaller. This increases the expected benefits from tax evasion, thus reducing the threshold for $l_{i}$ above which an individual will optimally decide to hide sources of income from the authorities. Consequently, the number of individuals who will evade their taxes increases (i.e., higher $\left.e_{t+1}\right)$. Similarly to the original version of the model, this dynamic complementarity may generate multiple, path-dependent equilibria in the dynamics of tax evasion. Particularly, using the specific functional form from (24) in Eq. (45), it can be shown that there are circumstances where the dynamics generate three steady state equilibria $\hat{e}_{l}<\hat{e}_{m}<\hat{e}_{h}$ such that $F^{\prime}\left(\hat{e}_{l}\right), F^{\prime}\left(\hat{e}_{h}\right) \in(0,1)$ and $F^{\prime}\left(\hat{e}_{m}\right)>1.28$

It is worth mentioning that this framework is conducive to the discussion of some additional policy implications, especially on policies targeted at improved tax enforcement. To clarify this point, consider Eq. (44) and (45) from which it is straightforward to establish that $\frac{\partial \hat{l}_{t+1}}{\partial \pi}>0$ and, therefore, $\frac{\partial F(\cdot)}{\partial \pi}<0$. In other words, a policy that can increase the probability of detecting tax evaders, could lead to a downward shift of the $F\left(e_{t}\right)$ curve - a shift of potentially such magnitude so as to establish $\hat{e}_{l}$ as the only long-run equilibrium. Once more, however, the cautionary arguments outlined at the end of Section 4 apply here as well. Particularly, in addition to the cost in terms of reduced spending for public infrastructure - an effect that could eradicate the positive impact of reduced tax evasion on growth - budgetary constraints could undermine the feasibility of an increase in $\pi$ that is sufficient enough to eliminate the presence of threshold effects.

\subsection{On the Return of the Storage Technology}

In the main part of the analysis, one of the underlying assumptions was that the excessive (relative to reported income) saving in the formal financial sector may act as a signal of an individual's tax evasion. For this reason, it was assumed that the undeclared income can be stored through an alternative technology that allows individuals to hide the traces of their misdemeanour and whose return $\left(q_{t+1}\right)$ is lower compared to the return offered by the formal financial sector $\left(r_{t+1}\right)$.

In this section, I shall revisit the model in the case where $\xi>1 \Leftrightarrow q_{t+1}>r_{t+1}$. Naturally, this would make the storage technology a more profitable option for all individuals in the economy - not only the ones who engage in tax evasion. For this reason, a necessary

${ }^{28}$ For example, with $\varphi=0.35, p=2, \xi=0.9, v=38, \kappa=0.9, m=0.95, \pi=0.13$ and $\beta=10$ we get the following solutions satisfying $e_{t+1}=e_{t}=\hat{e}$ in Eq. (45): $\hat{e}_{l} \approx 0.41, \hat{e}_{m} \approx 0.65$ and $\hat{e}_{h} \approx 0.98$. 
assumption to ensure that the declared income is deposited to financial intermediaries an outcome that is necessary to have a process of capital accumulation in the first place is that this storage technology is an "underground" one, accessible only to individuals who seek to blur the traces of their wrongdoing. Given this, it is straightforward to establish that the analysis and implications of the original set-up remain qualitatively intact. The utilities associated with each scenario are still given by Eq. (6), (8) and (10) in fact, for $\xi>1$ the condition $\xi+\varphi>1$ (a condition that ensured that evasion is a possibly meaningful option for an individual tax payer) is automatically satisfied and does not need to be assumed. Furthermore, the composite parameter terms in (12)-(14) still satisfy $\sigma>\eta>h$ given that the composite term $\sigma$ is increasing in $\xi$. Hence the dynamics of tax evasion are still given by Eq. (18), from which it is still possible to get multiple equilibria with the parametric conditions underlying Proposition 3.

All in all, the assumption $\xi \in(0,1)$ that was employed in the main part of the analysis was imposed purely as a technical device to ensure that the formal financial sector can attract saving deposits, hence making the process of capital accumulation possible; it does not have any bearing on the qualitative nature of the results. Indeed, these results hold even when $\xi>1$, as long as individuals have the incentive to deposit (at least a part of) their income to the saving device that generates the formation of capital.

\subsection{Intertemporal Consumption Choice}

This section revisits the problem under a setting where individuals have preferences for consumption during both periods of their adulthood. Such a setting introduces significant technical complications. For this reason, some additional assumptions are made in order to make the analysis as tractable as possible. Firstly, I shall normalise the value of $\xi$ to unity. Secondly, the lifetime utility takes the $\log$-linear form $c_{t+1} c_{t+2}^{b}$, where $0<b \leq 1$.

Consider an individual who decides to be honest with the declaration of her income and denote saving by $s_{t+1}$. Her consumption expenditures during youth and old-age are given by $c_{t+1}=(1-\varphi) w_{t+1}(1+l)-s_{t+1}$ and $c_{t+2}=r_{t+2} s_{t+1}$ respectively. Maximising lifetime utility subject to these constraints yields $s_{t+1}=\frac{b}{1+b}(1-\varphi) w_{t+1}(1+l)$ - a result that, together with the budget constraints, can be substituted back to the utility function to derive

$$
\overline{u_{t+1}}=\frac{b^{b}}{(1+b)^{1+b}} r_{t+2}^{b} w_{t+1}^{1+b}[(1-\varphi)(1+l)]^{1+b} .
$$

Now consider a taxpayer who has decided to underreport her actual income. If she is successful in remaining undetected, her consumption expenditures during youth will be determined by $c_{t+1}=(1-\varphi+l) w_{t+1}-s_{t+1}$ whereas having her wrongdoing exposed will result in her consumption expenditures during youth being determined by 
$c_{t+1}=[1-\varphi+(1-p \varphi) l] w_{t+1}-s_{t+1}$. In both cases, her consumption during maturity is determined by the return to her saving, i.e., $c_{t+2}=r_{t+2} s_{t+1}$. It follows that her expected utility is

$$
\begin{aligned}
& \left(1-\pi_{t+1}(i)\right)\left\{\left[(1-\varphi+l) w_{t+1}-s_{t+1}\right]\left(r_{t+2} s_{t+1}\right)^{b}\right\} \\
& +\pi_{t+1}(i)\left(1-\psi_{t+1}\right)\left\{\left[(1-\varphi+(1-p \varphi) l) w_{t+1}-s_{t+1}\right]\left(r_{t+2} s_{t+1}\right)^{b}\right\},
\end{aligned}
$$

where, similarly to the original version of the model, $\psi_{t+1}$ is the psychological cost affecting the lifetime utility of a person whose misdemeanour will be exposed. Maximising the expression in (47), and substituting (17), it is straightforward to show that the individual's optimal saving is

$$
s_{t+1}=\frac{b}{1+b} w_{t+1}\left\{1-\varphi+l-p \varphi l \frac{\pi_{t+1}(i)\left[1-\Psi\left(e_{t}\right)\right]}{1-\pi_{t+1}(i) \Psi\left(e_{t}\right)}\right\} .
$$

Given $\Psi^{\prime}\left(e_{t}\right)<0$, it follows that $\frac{\partial s_{t+1}}{\partial e_{t}}<0$. This introduces an additional effect that exacerbates the persistency of the negative impact of tax evasion on saving and capital accumulation. In addition to the impact of the contemporaneous magnitude of tax evasion on capital accumulation, now we can see that the past incidence of tax evasion $\left(e_{t}\right)$ can exert an additional pressure on saving and capital formation, thus magnifying its detrimental impact on growth performance. The risk of being detected and paying the financial penalty associated with tax evasion, reduces the expected disposable income out of which people save. The presence of the psychic cost factor reduces the effective weight on the lifetime utility that the person is expected to enjoy if this possibility materialises, thus inducing her to smooth her consumption profile by increasing her saving in response to an increase in $\psi_{t+1}$. Consequently, $\frac{\partial s_{t+1}}{\partial e_{t}}<0$ because the higher incidence of tax evasion in the past mitigates the lifetime utility loss due factors such as social stigma, reputation damage etc.

Substituting the saving function back to (47), and using the composite terms $\sigma \equiv 1-\varphi+l$ and $h \equiv 1-\varphi+(1-p \varphi) l$, we can eventually write the expected utility of a person who evades her taxes according to

$$
u_{t+1}(i)=\frac{b^{b}}{(1+b)^{1+b}} r_{t+2}^{b} w_{t+1}^{1+b} \times M,
$$

where the composite term summarised by $M$ is the following:

$$
\begin{aligned}
& \left(1-\pi_{t+1}(i)\right)\left\{\sigma+b p \varphi l \frac{\pi_{t+1}(i)\left[1-\Psi\left(e_{t}\right)\right]}{1-\pi_{t+1}(i) \Psi\left(e_{t}\right)}\right\}\left\{\sigma-p \varphi l \frac{\pi_{t+1}(i)\left[1-\Psi\left(e_{t}\right)\right]}{1-\pi_{t+1}(i) \Psi\left(e_{t}\right)}\right\}^{b}+ \\
& \left.\pi_{t+1}(i)\right)\left[1-\Psi\left(e_{t}\right)\right] \times\left\{h-b p \varphi l \frac{1-\pi_{t+1}(i)}{1-\pi_{t+1}(i) \Psi\left(e_{t}\right)}\right\}\left\{h-b p \varphi l \frac{1-\pi_{t+1}(i)}{1-\pi_{t+1}(i) \Psi\left(e_{t}\right)}\right\}^{b} .
\end{aligned}
$$


An individual will decide to engage in tax evasion as long as $u_{t+1}(i)>\overline{u_{t+1}}$ or, equivalently, $M>[(1-\varphi)(1+l)]^{1+b}$. Obviously, the expression in (49) is too complicated to yield an analytical solution for a critical value of $\pi_{t+1}(i)$ that satisfies $u_{t+1}(i)=\overline{u_{t+1}} \Leftrightarrow M=[(1-\varphi)(1+l)]^{1+b}$. For this reason, I shall undertake the remaining analysis by means of a numerical example. Firstly, I set $b=1$ in (49), i.e., the only case in which a closed-form solution is possible. It follows that (49) can be rewritten as

$$
\begin{aligned}
& \left(1-\pi_{t+1}(i)\right)\left\{\sigma^{2}-\left(p \varphi l \frac{\pi_{t+1}(i)\left[1-\Psi\left(e_{t}\right)\right]}{1-\pi_{t+1}(i) \Psi\left(e_{t}\right)}\right)^{2}\right\}+ \\
& \left.\pi_{t+1}(i)\right)\left[1-\Psi\left(e_{t}\right)\right]\left\{h^{2}-\left(p \varphi l \frac{1-\pi_{t+1}(i)}{1-\pi_{t+1}(i) \Psi\left(e_{t}\right)}\right)^{2}\right\} .
\end{aligned}
$$

For expositional purposes, I shall also set parameter values $p=1.25, \varphi=0.35$ and $l=1$. In this case, $u_{t+1}(i)=\overline{u_{t+1}}$ defines a critical value $\hat{\pi}_{t+1}$ so that the individuals who will find optimal to evade their tax payments are those with $\pi_{t+1}(i)<\hat{\pi}_{t+1}$. It follows that $e_{t+1}=\hat{\pi}_{t+1}$ or, using the specific solution for $\hat{\pi}_{t+1}$,

$$
e_{t+1}=\frac{1.275+2.545 \Psi\left(e_{t}\right)-1.4 \sqrt{0.563+1.425 \Psi\left(e_{t}\right)-0.028\left[\Psi\left(e_{t}\right)\right]^{2}}}{2\left\{0.141+0.993 \Psi\left(e_{t}\right)+1.756\left[\Psi\left(e_{t}\right)\right]^{2}\right\}}=F\left(e_{t}\right) .
$$

Taking account that $\Psi^{\prime}\left(e_{t}\right)<0$, it can be shown that the above expression satisfies $F^{\prime}\left(e_{t}\right)>0$ as with the original version of the model. Furthermore, note that the dynamics of tax evasion can generate multiple, path-dependent equilibria, similar to the situation that was pointed out in Section 3. For example, using the functional form of (24) in Eq. (51), and setting $\beta=10, m=0.95, k=1$ and $v=800$, we can obtain three steady state equilibria. $\hat{e}_{l} \approx 0.33, \hat{e}_{m} \approx 0.56$ and $\hat{e}_{h} \approx 0.78$ such that $F^{\prime}\left(\hat{e}_{l}\right), F^{\prime}\left(\hat{e}_{h}\right) \in(0,1)$ and $F^{\prime}\left(\hat{e}_{m}\right)>1$.

\section{Conclusion}

The purpose of this paper was to identify the sources of tax evasion persistence, and examine their implications for economic growth. I have shown that introducing a dynamic externality (in the form of a cultural norm), determining the social contemptibility of tax fraud, may generate multiple, path-dependent equilibria in the dynamics of tax evasion. Given the latter's effect on capital accumulation and growth, I have illustrated that this multiplicity can impinge on the overall economic environment. Even when the structural characteristics of tax enforcement and capital formation, as well as the current capital stock, are given, the economy's development path will depend crucially on the pre-existing conditions with respect to the magnitude of tax evasion. This is because the cultural norm acts as a propagation mechanism that amplifies current imbalances in the degree of tax compliance, thus embedding them to the characteristics that determine the economy's long-term prospects. 
As we have seen, what is crucial when it comes to path-dependent equilibria is not the initial stock of capital, but the initial level of tax compliance. One could argue that introducing an additional component in the determinants of tax auditing - a component that would make the auditing probability increasing in the capital stock - would imply that the initial stock of capital could also play a role in determining the economy's development path. There are two arguments that can address this point. Firstly, even if this is the case, such a framework would not change the main narrative of the existing framework. As long as multiple equilibria exist, there will still be circumstances where, for a given capital stock, the initial magnitude of tax evasion would shape the economy's long-term dynamics. Secondly, there are many authors who claim that the extent to which governments can increase the rate at which they successfully apprehend cases of tax evasion, simply by increasing the resources devoted to tax enforcement, can sometimes be limited. One obvious reason may relate to budgetary constraints, but there are additional arguments as well. According to Selmrod and Yitzhaki (1987), comparing the increase in resources devoted towards tax enforcement to the increase in expected revenue achieved through this process, does not always indicate a net economic gain. In many circumstances, the alleged tax evaders will try to repudiate the claims against them, thus leading to a protracted (and certainly costly) litigation process. All these are circumstances that question the extent to which the increase of the resources devoted to tax enforcement would always result in an analogous improvement of tax compliance, assuming that such an increase is feasible in the first place - something that is not always the case.

The current framework absconded from some features that pertain to the broad issue of tax fraud, in order to keep the analysis tightly focused on the issue of tax evasion persistence under cultural norms, and its implications for capital formation and growth. Certainly, one could envisage various extensions that will enrich the existing results and broaden both their economic and their policy implications. For example, corporate tax evasion (e.g., Chen and Chu 2005) can be an additional element of tax fraud with potentially interesting implications for economic dynamics. The issue of networking and collusion among tax evaders (e.g., Boadway et al. 2002) represents yet another social/cultural dimension with significant repercussions for the tax evasion-economic growth nexus. Furthermore, tax evasion may have additional repercussions in frameworks, such as the one of Espinosa-Vega and Yip (2002), where the government has various means of financing at its disposal. All these are indubitably important issues, hence representing a fruitful avenue for future research.

\section{Appendix}

\section{Proof of Proposition 1}

Combining (12)-(16), it is straightforward to show that 


$$
\begin{gathered}
\frac{\partial e_{t+1}}{\partial \psi_{t+1}}=-\frac{(\sigma-\eta) h}{\left[\sigma-\left(1-\psi_{t+1}\right) h\right]^{2}}<0, \\
\frac{\partial e_{t+1}}{\partial p}=\frac{\partial e_{t+1}}{\partial h} \frac{\partial h}{\partial p}=-\frac{\left.\varphi l\left(1-\psi_{t+1}\right)(\sigma-\eta) \theta[1-\varphi+(1-p \varphi) l)\right]^{\theta-1}}{\left[\sigma-\left(1-\psi_{t+1}\right) h\right]^{2}}<0, \\
\frac{\partial e_{t+1}}{\partial \xi}=\frac{\partial e_{t+1}}{\partial \sigma} \frac{\partial \sigma}{\partial \xi}=\frac{\left[\eta-\left(1-\psi_{t+1}\right) h\right] \theta(1-\varphi+\xi l)^{\theta-1} l}{\left[\sigma-\left(1-\psi_{t+1}\right) h\right]^{2}}>0 .
\end{gathered}
$$

In order to analyse $\frac{\partial e_{t+1}}{\partial \theta}$, note that we can rewrite

$$
e_{t+1}=\frac{\varepsilon^{\theta}\left(o^{\theta}-1\right)}{(o \varepsilon)^{\theta}-\left(1-\psi_{t+1}\right)},
$$

where

$$
\begin{gathered}
\varepsilon \equiv \frac{(1-\varphi)(1+l)}{1-\varphi+(1-p \varphi) l}>1, \\
o \equiv \frac{1-\varphi+\xi l}{(1-\varphi)(1+l)}>1 .
\end{gathered}
$$

Therefore, we have

$$
\begin{gathered}
\frac{\partial e_{t+1}}{\partial \theta}=\frac{\varepsilon^{\theta} \ln (\varepsilon)\left(o^{\theta}-1\right)}{(o \varepsilon)^{\theta}-\left(1-\psi_{t+1}\right)}+\frac{\varepsilon^{\theta}\left\{o^{\theta} \ln (o)\left[(o \varepsilon)^{\theta}-\left(1-\psi_{t+1}\right)\right]-(o \varepsilon)^{\theta} \ln (o \varepsilon)\left(o^{\theta}-1\right)\right\}}{\left[(o \varepsilon)^{\theta}-\left(1-\psi_{t+1}\right)\right]^{2}} \Rightarrow \\
\frac{\partial e_{t+1}}{\partial \theta}=\frac{\varepsilon^{\theta}}{(o \varepsilon)^{\theta}-\left(1-\psi_{t+1}\right)}\left\{\ln (\varepsilon)\left(o^{\theta}-1\right)+o^{\theta} \ln (o)-\frac{(o \varepsilon)^{\theta} \ln (o \varepsilon)\left(o^{\theta}-1\right)}{(o \varepsilon)^{\theta}-\left(1-\psi_{t+1}\right)}\right\} .
\end{gathered}
$$

Note that the sign of the expression in (A1) depends on the sign of the expression inside brackets - an expression that is increasing in $\psi_{t+1}$. Thus, if it is positive for $\psi_{t+1}=0$ then it is certainly positive for $\psi_{t+1} \in(0,1)$ as well. In other words, it is sufficient to show that

$$
\ln (\varepsilon)\left(o^{\theta}-1\right)+o^{\theta} \ln (o)-\frac{(o \varepsilon)^{\theta} \ln (o \varepsilon)\left(o^{\theta}-1\right)}{(o \varepsilon)^{\theta}-1}>0,
$$

holds. Note that we can write the LHS of (A2) as

$$
\begin{gathered}
\ln (\varepsilon)\left(o^{\theta}-1\right)+o^{\theta} \ln (o)+\ln (o)-\ln (o)-\frac{(o \varepsilon)^{\theta} \ln (o \varepsilon)\left(o^{\theta}-1\right)}{(o \varepsilon)^{\theta}-1} \Rightarrow \\
\ln (\varepsilon)\left(o^{\theta}-1\right)+\ln (o)\left(o^{\theta}-1\right)+\ln (o)-\frac{(o \varepsilon)^{\theta} \ln (o \varepsilon)\left(o^{\theta}-1\right)}{(o \varepsilon)^{\theta}-1} \Rightarrow \\
\ln (o \varepsilon)\left(o^{\theta}-1\right)+\ln (o)-\frac{(o \varepsilon)^{\theta} \ln (o \varepsilon)\left(o^{\theta}-1\right)}{(o \varepsilon)^{\theta}-1} \Rightarrow \\
\ln (o \varepsilon)\left(o^{\theta}-1\right)\left[1-\frac{(o \varepsilon)^{\theta}}{(o \varepsilon)^{\theta}-1}\right]+\ln (o),
\end{gathered}
$$

which can be factorised with $o^{\theta}-1$ to get

$$
\left[\frac{\ln (o)}{o^{\theta}-1}-\frac{\ln (o \varepsilon)}{(o \varepsilon)^{\theta}-1}\right]\left(o^{\theta}-1\right) \text {. }
$$


Now consider $b(x)=\frac{\ln (x)}{\chi^{\theta}-1}$ for $\chi>1$. If $b^{\prime}(x)<0$ then, by virtue of $o>1$ and $\varepsilon>1$, the expression in (A3) is positive, thus verifying that $\frac{\partial e_{t+1}}{\partial \theta}>0$ as well. It is

$$
b^{\prime}(x)=\frac{1}{\left(x^{\theta}-1\right) x}\left[1-\frac{\tilde{x}}{\tilde{x}-1} \ln (\tilde{x})\right]
$$

where $\tilde{\chi} \equiv \chi^{\theta}$. Given this, it is sufficient to show that $\ln (\tilde{x})>\frac{\tilde{x}-1}{\tilde{x}}$. This is true because $\ln (1)=0$ and $\frac{\partial \ln \tilde{x}}{\partial \tilde{x}}>\frac{\partial((\tilde{x}-1) / \tilde{x})}{\partial \tilde{x}} \Leftrightarrow \frac{1}{\tilde{x}}>\frac{1}{\tilde{x}^{2}}$ for $\tilde{x}>1$

\section{Proof of Lemma 1}

Define $\zeta=v e^{\beta}$. Then, given (26), the sign of $B^{\prime}(e)$ depends on the sign of $\sigma-h+\frac{h m \kappa}{\kappa+\zeta}-\frac{h m \kappa \beta v e^{\beta}}{(\kappa+\zeta)^{2}}$ or, after factorizing with $(\kappa+\zeta)^{-2}$, manipulating algebraically and using (27) and (28),

$$
J(\zeta)=\zeta^{2}-2 \zeta \kappa\left[\frac{h m(\beta-1)}{2(\sigma-h)}-1\right]+\kappa^{2}\left(\frac{h m}{\sigma-h}+1\right)=\zeta^{2}-2 \zeta \kappa \mu+\kappa^{2} \delta .
$$

From (A4), it is $J(0)=\kappa^{2} \delta>0, J^{\prime}(\zeta)=2(\zeta-\kappa \mu)$ and $J^{\prime \prime}(\zeta)=2$. Now consider $\tilde{\zeta}=\kappa \mu$ such that $J^{\prime}(\tilde{\zeta})=0$. Substituting in (A4) we have $(\kappa \mu)^{2}-2(\kappa \mu)^{2}+\kappa^{2} \delta$ or

$$
\kappa^{2}\left(\delta-\mu^{2}\right) .
$$

As long as $\delta>\mu^{2}$ then $J(\zeta)>0 \quad \forall \zeta$ and, therefore, $B^{\prime}(e)>0 \quad \forall e$. Using the composite terms in (27) and (28), this is the case when

$$
\begin{gathered}
\frac{h m}{\sigma-h}+1>\left[\frac{h m(\beta-1)}{2(\sigma-h)}-1\right]^{2} \Rightarrow \\
\frac{h m}{\sigma-h}+1>\frac{(h m)^{2}(\beta-1)^{2}}{4(\sigma-h)^{2}}+1-\frac{h m(\beta-1)}{\sigma-h} \Rightarrow \\
\frac{(\beta-1)^{2}}{\beta}<\frac{4(\sigma-h)}{h m} .
\end{gathered}
$$

However, when the condition in (A6) does not hold, i.e., when $\mu^{2}>\delta$, then there are two values $\zeta^{*}, \zeta^{* *}>0\left(\zeta^{* *}>\zeta^{*}\right)$ for which $J(\zeta)=0$. These are the roots of the quadratic equation in (A4) and they are given by

$$
\begin{aligned}
& \zeta^{*}=\kappa\left(\mu-\sqrt{\mu^{2}-\delta}\right), \\
& \zeta^{* *}=\kappa\left(\mu+\sqrt{\mu^{2}-\delta}\right) .
\end{aligned}
$$

Therefore $J(\zeta)=\left(\zeta-\zeta^{*}\right)\left(\zeta-\zeta^{* *}\right)$, meaning that 


$$
J(\zeta)\left\{\begin{array}{clc}
>0 & \text { if } & \zeta<\zeta^{*} \\
<0 & \text { if } & \zeta^{*}<\zeta<\zeta^{* *} . \\
>0 & \text { if } & \zeta>\zeta^{* *}
\end{array}\right.
$$

Now, recall that $\zeta=v e^{\beta}$ and that the sign of $J(\zeta)=J\left(v e^{\beta}\right)$ determines the sign of $B^{\prime}(e)$. Given (A7), (A8) and Assumption 1, we can define $e^{*}$ and $e^{* *}\left(e^{*}<e^{* *}<1\right)$ given by

$$
\begin{aligned}
e^{*} & =\left[\frac{\kappa}{v}\left(\mu-\sqrt{\mu^{2}-\delta}\right)\right]^{\frac{1}{\beta}}, \\
e^{* *} & =\left[\frac{\kappa}{v}\left(\mu+\sqrt{\mu^{2}-\delta}\right)\right]^{\frac{1}{\beta}},
\end{aligned}
$$

respectively. Hence

$$
B^{\prime}(e)\left\{\begin{array}{ccc}
>0 & \text { if } & e<e^{*} \\
<0 & \text { if } & e^{*}<e<e^{* *} \\
>0 & \text { if } & e>e^{* *}
\end{array},\right.
$$

which completes the proof.

\section{Proof of Proposition 2}

Suppose that the condition in (A6) holds. In this case, $B^{\prime}(e)>0$. Together with $B(0)=0$ and $B(1)>1$, it follows that there is a unique $\hat{e}$ such that $B(\hat{e})=1 \Leftrightarrow \hat{e}=F(\hat{e})$ and $B^{\prime}(\hat{e})>0$. Given (19) and (22), we have

$$
\begin{gathered}
B^{\prime}(\hat{e})>0 \Rightarrow \\
\frac{F(\hat{e})-\hat{e} F^{\prime}(\hat{e})}{(F(\hat{e}))^{2}}>0 \Rightarrow \\
\hat{e}>\hat{e} F^{\prime}(\hat{e}) \Rightarrow \\
F^{\prime}(\hat{e})<1,
\end{gathered}
$$

i.e., $\hat{e}$ is a stable equilibrium.

Even when the condition in (A6) does not hold, then if either $B\left(e^{*}\right)<1$ or $B\left(e^{* *}\right)>1$ the analysis of Lemma 1 indicates that, again, there is a unique $\hat{e}$ such that $B(\hat{e})=1 \Leftrightarrow \hat{e}=F(\hat{e})$ and $B^{\prime}(e)>0$. By appealing to (A9), this steady state equilibrium is stable.

\section{Proof of Proposition 3}

Suppose that both $B\left(e^{*}\right)>1$ and $B\left(e^{* *}\right)<1$ hold, whereas the condition in (A6) is not satisfied. By virtue of Lemma 1, we can conclude that the following steady state equilibria exist: $\hat{e}_{l} \in\left(0, e^{*}\right)$ such that $B\left(\hat{e}_{l}\right)=1 \Leftrightarrow \hat{e}_{l}=F\left(\hat{e}_{l}\right)$ and $B^{\prime}\left(e_{l}\right)>0 ; \hat{e}_{m} \in\left(e^{*}, e^{* *}\right)$ such that $B\left(\hat{e}_{m}\right)=1 \Leftrightarrow \hat{e}_{m}=F\left(\hat{e}_{m}\right)$ and $B^{\prime}\left(\hat{e}_{m}\right)<0$; and $\hat{e}_{h} \in\left(e^{* *}, 1\right)$ such that $B\left(\hat{e}_{h}\right)=1 \Leftrightarrow \hat{e}_{h}=F\left(\hat{e}_{h}\right)$ 
and $B^{\prime}\left(\hat{e}_{h}\right)>0$. The stability properties of these equilibria can be verified by appealing to the result in (A9).

\section{Proof of Proposition 4}

It is $\omega_{e_{t}}\left(k_{t}, e_{t}\right)=\frac{\partial \omega\left(k_{t}, e_{t}\right)}{\partial Q_{G}\left(e_{t}\right)} Q_{G}^{\prime}\left(e_{t}\right)+\frac{\partial \omega\left(k_{t}, e_{t}\right)}{\partial Q_{K}\left(e_{t}\right)} Q_{K}^{\prime}\left(e_{t}\right)$. Combining (37), (39) and (40) we can check that this expression is equal to $v l\left[A^{\frac{1}{r}}+\frac{(1-a) \varphi}{n+l} Q_{G}\left(e_{t}\right)\right]^{r} \times\{\cdot\}$, where

$$
\{\cdot\}=\frac{r\left(p e_{t}-1\right) \frac{(1-a) \varphi}{n+l} Q_{K}\left(e_{t}\right)}{A^{\frac{1}{r}}+\frac{(1-a) \varphi}{n+l} Q_{G}\left(e_{t}\right)}-\left(1-\frac{1-p \varphi}{1-\varphi} e_{t}\right) .
$$

Given that $\frac{1-p \varphi}{1-\varphi}<1$, it is sufficient to show that $p e_{t}<1$ in order to prove that (A10) is unambiguously negative. Recall that in Proposition 1 I showed that $\frac{\partial e_{t+1}}{\partial \theta}>0$, meaning that if $p e_{t}<1$ for $\theta=1$, then this is certainly true for every $\theta \in(0,1)$. Substituting $\theta=1$ in (12)-(16) yields

$$
e_{t+1}=\frac{l(\xi+\varphi-1)}{1-\varphi+\xi l-\left(1-\psi_{t+1}\right)[1-\varphi+(1-p \varphi) l]} .
$$

Thus, using (A11), we need to establish that

$$
p l(\xi+\varphi-1)<1-\varphi+\xi l-\left(1-\psi_{t+1}\right)[1-\varphi+(1-p \varphi) l] .
$$

This inequality can be rewritten as

$$
\begin{gathered}
p l \xi-p l(1-\varphi)<\xi l-(1-p \varphi) l+\psi_{t+1}[1-\varphi+(1-p \varphi) l] \Rightarrow \\
\xi-(1-p \varphi)-p \xi+p(1-\varphi)+\frac{\psi_{t+1}[1-\varphi+(1-p \varphi) l]}{l}>0 \Rightarrow \\
(p-1)(1-\xi)+\frac{\psi_{t+1}[1-\varphi+(1-p \varphi) l]}{l}>0,
\end{gathered}
$$

which holds by virtue of $\xi \in(0,1)$ and $p>1$, thus completing the proof.

\section{Proof of Lemma 2}

The dynamic equilibrium of the economy is summarised by the system of non-linear difference equations

$$
\begin{aligned}
& k_{t+1}=\omega\left(k_{t}, e_{t}\right), \\
& e_{t+1}=F\left(k_{t}, e_{t}\right),
\end{aligned}
$$

that are given in (37) and (18) respectively, and from which we know that $\omega_{k_{t}}\left(k_{t}, e_{t}\right)>0$, $\omega_{e_{t}}\left(k_{t}, e_{t}\right)<0, F_{k_{t}}\left(k_{t}, e_{t}\right)=0$ and $F_{e_{t}}\left(k_{t}, e_{t}\right)>0$. Defining steady state solutions as those for 
which $k_{t+1}=k_{t}=\hat{k}$ and $e_{t+1}=e_{t}=\hat{e}$, we can use this information to construct the Jacobian matrix

$$
\left(\begin{array}{cc}
\omega_{k_{t}}(\hat{k}, \hat{e}) & \omega_{e_{t}}(\hat{k}, \hat{e}) \\
F_{k_{t}}(\hat{k}, \hat{e}) & F_{e_{t}}(\hat{k}, \hat{e})
\end{array}\right),
$$

whose trace and determinant are given by $T=\omega_{k_{t}}(\hat{k}, \hat{e})+F_{e_{t}}(\hat{k}, \hat{e})$ and $D=\omega_{k_{t}}(\hat{k}, \hat{e}) F_{e_{t}}(\hat{k}, \hat{e})$ respectively (recall that $F_{k_{t}}=0 \quad \forall e_{t}$ ). Given these, the eigenvalues $\lambda_{1}$ and $\lambda_{2}$ are the roots of the polynomial $\lambda^{2}-\lambda T+D$, i.e.,

$$
\lambda_{1}=\frac{T-\sqrt{T^{2}-4 D}}{2}, \lambda_{2}=\frac{T+\sqrt{T^{2}-4 D}}{2} .
$$

We can verify that these eigenvalues are real and distinct as long as $T^{2}>4 D$. Indeed, using the fact that $F_{e_{t}}\left(k_{t}, e_{t}\right)=F^{\prime}\left(e_{t}\right) \forall k_{t}$, we have

$$
\begin{gathered}
T^{2}-4 D= \\
\left(\omega_{k_{t}}(\hat{k}, \hat{e})\right)^{2}+\left(F^{\prime}(\hat{e})\right)^{2}+2 \omega_{k_{t}}(\hat{k}, \hat{e}) F^{\prime}(\hat{e})-4 \omega_{k_{t}}(\hat{k}, \hat{e}) F^{\prime}(\hat{e})= \\
\left(\omega_{k_{t}}(\hat{k}, \hat{e})\right)^{2}+\left(F^{\prime}(\hat{e})\right)^{2}-2 \omega_{k_{t}}(\hat{k}, \hat{e}) F^{\prime}(\hat{e})= \\
\left(\omega_{k_{t}}(\hat{k}, \hat{e})-F^{\prime}(\hat{e})\right)^{2}>0 .
\end{gathered}
$$

Let us set $k_{t+1}=k_{t}=\hat{k}$ and $e_{t+1}=e_{t}=\hat{e}$. Applying these steady state conditions in Eq. (37) yields

$$
\hat{k}=\left\{v\left[A^{\frac{1}{r}}+\frac{(1-a) \varphi}{n+l} Q_{G}(\hat{e})\right]^{r} Q_{K}(\hat{e})\right\}^{\frac{1}{1-a}} \equiv \Omega(\hat{e}),
$$

where $\Omega^{\prime}(\hat{e})<0$ follows from the analysis in the proof of Proposition 4. From Proposition 3, we know that there exist three steady state equilibria $\hat{e}_{h}>\hat{e}_{m}>\hat{e}_{l}$ which we can substitute in (A13) to get

$$
\begin{gathered}
\hat{k}_{l}=\Omega\left(\hat{e}_{h}\right), \\
\hat{k}_{m}=\Omega\left(\hat{e}_{m}\right), \\
\hat{k}_{h}=\Omega\left(\hat{e}_{l}\right),
\end{gathered}
$$

where $\hat{k}_{h}>\hat{k}_{m}>\hat{k}_{l}$ by virtue of $\Omega^{\prime}(\hat{e})<0$.

Now consider the eigenvalues in (A12). Since $T^{2}-4 D=\left(\omega_{k_{t}}(\hat{k}, \hat{e})-F^{\prime}(\hat{e})\right)^{2}$ it follows that $\lambda_{1}=F^{\prime}(\hat{e})$ and $\lambda_{2}=\omega_{k_{t}}(\hat{k}, \hat{e})$. From (37), we have

$$
\omega_{k_{t}}\left(k_{t}, e_{t}\right)=a v\left[A^{\frac{1}{r}}+\frac{(1-a) \varphi}{n+l} Q_{G}\left(e_{t}\right)\right]^{r} Q_{K}\left(e_{t}\right) k_{t}^{a-1},
$$

which we can evaluate at the steady state of (A13) to get

$$
\omega_{k_{t}}(\hat{k}, \hat{e})=a \in(0,1) \forall \hat{k}, \hat{e} \text {. }
$$


Furthermore, we know from Proposition 3 that $F^{\prime}\left(\hat{e}_{l}\right), F^{\prime}\left(\hat{e}_{h}\right) \in(0,1)$ and $F^{\prime}\left(\hat{e}_{m}\right)>1$. Thus for $\left(\hat{k}_{l}, \hat{e}_{h}\right)$ and $\left(\hat{k}_{h}, \hat{e}_{l}\right)$ we have $\lambda_{1}, \lambda_{2} \in(0,1)$ meaning that these pairs of equilibria are stable. However, for $\left(\hat{k}_{m}, \hat{e}_{m}\right)$ we have $\lambda_{1}>1$ and $\lambda_{2} \in(0,1)$. Consequently, this pair of steady state equilibria is not stable.

\section{References}

Acemoglu, D.: Introduction to Modern Economic Growth. Princeton University Press, Princeton (2009).

Allingham, M.G., Sandmo, A.: Income tax evasion: A theoretical analysis. J. Public Econ. 1, 323-338 (1972).

Alm, J.: Measuring, explaining, and controlling tax evasion: Lessons from theory, experiments, and field studies. Int. Tax Public Finance 19, $54-77$ (2012).

Andreoni, J., Erard, B., Feinstein, J.: Tax compliance. J. Econ. Lit. 36, 818-860 (1998).

Artavanis, N.T., Morse, A., Tsoutsoura, M.: Tax evasion across industries: Soft credit evidence from Greece. Research paper no. 12-05, Booth School of Business, University of Chicago (2012).

Azariadis, C., Smith, B.: Financial intermediation and regime switching in business cycles. Amer. Econ. Rev. 88, 516-536 (1998).

Baldry, J.: The enforcement of income tax laws: Efficiency implications. Econ. Rec. 60, 156-159 (1984).

Barbiero, O., Cournède, B.: New econometric estimates of long-term growth effects of different areas of public spending. Working paper no. 1100, Economics Department, OECD (2013).

Barr, A., Serra, D.: Corruption and culture: An experimental analysis. J. Public Econ. 94, 862-869 (2010).

Barro, R.J., Sala-i-Martin, X.: Public finance in models of economic growth. Rev. Econ. Stud. 59, 645-661 (1992).

Bernasconi, M.: Tax evasion and orders of risk aversion. J. Public Econ. 67, 123-134 (1998).

Bethencourt, C., Kunze, L.: Tax evasion, social norms and economic growth. Working paper no. 48427, Munich Personal RePEc Archive (2013).

Blackburn, K., Bose, N., Capasso, S.: Tax evasion, the underground economy, and financial development. J. Econ. Behav. Organ. 83, 243-253 (2012).

Blackburn, K., Bose, N., Haque, E.M.: The incidence and persistence of corruption in economic development. J. Econ. Dynam. Control 30, 2447-2467 (2006).

Boadway, R., Marceau, N., Mongrain, S.: Joint tax evasion. Can. J. Econ. 35, 417-435 (2002).

Busato, F., Chiarini, B.: Market and underground activities in a two-sector dynamic equilibrium model. Econ. Theory 23, 831-861 (2004). 
Canta, C., Pestieau, P., Thibault, E.: Long-term care and capital accumulation: the impact of the State, the market and the family. Econ. Theory 61, 755-785 (2016).

Chen, B.L.: Tax evasion in a model of endogenous growth. Rev. Econ. Dynam. 6, 381-403 (2003).

Chen, K.P., Chu, C.Y.C.: Internal control versus external manipulation: A model of corporate income tax evasion. RAND J. Econ. 36, 151-164 (2005).

Ciccarone, G., Giuli, F., Marchetti, E.: Search frictions and labor market dynamics in a real business cycle model with undeclared work. Econ. Theory (forthcoming).

Clotfelter, C.: Tax evasion and tax rates: An analysis of individual returns. Rev. Econ. Statist. 65, 363-373 (1983).

Cooper; R., John, A.: Coordinating coordination failures in Keynesian models. Quart. J. Econ. 103, 441-463 (1988).

Cremer, H., Gahvari, F.: Tax evasion, concealment and the optimal linear income tax. Scand. J. Econ. 96, 219-239 (1994).

Cremer, H., Gahvari, F.: Tax evasion and the optimum general income tax. J. Public Econ. 60, 235-249 (1996).

De Soto, H.: The Other Path: The Invisible Revolution in the Third World. Harper and Row, New York (1989).

DeBacker, J., Bradley, T.H., Tran, A.: Importing corruption culture from overseas: Evidence from corporate tax evasion in the United States. J. Finan. Econ. 117, 122-138 (2015).

Espinosa-Vega, M.A., Yip, C.K.: Government financing in an endogenous growth model with financial market restrictions. Econ. Theory 20, 237-257 (2002).

Feinstein, J.S.: An econometric analysis of income tax evasion and its detection. RAND J. Econ. 22, 14-35 (1991).

Frey, B.S.: A constitution for knaves crowds out civic virtues. Econ. J. 107, 1043-1053 (1997).

Gächter, S.: Conditional cooperation: Behavioral regularities from the lab and the field and their policy implications. In: Frey, B.S., Stutzer, S. (eds.) Economics and Psychology: A Promising New Cross-Disciplinary Field, pp. 1423-1470. MIT Press, Cambridge MA (2007).

Gordon, J.F.P.: Individual morality and reputation costs as deterrents to tax evasion. Europ. Econ. Rev. 33, 797-805 (1989).

Grasmick, H.G., Scott, W.J.: Tax evasion and mechanisms of social control: A comparison with grand and petty theft. J. Econ. Psych. 2, 213-230 (1982).

Hashimzade, N., Myles, G.D., Page, F., Rablen, M.D.: Social networks and occupational choice: The endogenous formation of attitudes and beliefs about tax compliance. J. Econ. Psych. 40, 134-146 (2014).

Johannesen, N., Zucman, G. The end of bank secrecy? An evaluation of the G20 tax haven crackdown. Am. Econ. J.: Econ Policy 6, 65-91 (2014). 
Johnston, M.: A brief history of anticorruption agencies. In: Schedler, A., Diamond, L., Plattner, M.F. (eds.) The Self-Restraining State: Power and Accountability in New Democracies, pp. 217-226. Lynne Rienner Publishers, Boulder (1999).

Kafkalas, S., Kalaitzidakis, P., Tzouvelekas, V.: Tax evasion and public expenditures on tax revenue services in an endogenous growth model. Europ. Econ. Rev. 70, 438-453 (2014).

Kim, Y.: Income distribution and equilibrium multiplicity in a stigma-based model of tax evasion. J. Public Econ. 86, 1591-1616 (2003).

Litina, A., Palivos, T.: Corruption, tax evasion, and social values. Discussion paper no. 2014-10, Centre for Research in Economic Analysis, University of Luxemburg (2014).

Nam, C.W., Parsche, R., Schaden, B.: Measurement of value added tax evasion in selected EU Countries on the basis of national accounts data. Working paper no. 431, CESIfo (2001).

Pestieau, P., Possen, U.M.: Tax evasion and occupational choice. J. Public Econ. 45, 107125 (1991).

Pommerehne, W.W., Weck-Hannemann, H.: Tax rates, tax administration and income tax evasion in Switzerland. Public Choice 88, 161-170 (1996).

Roubini, N., Sala-i-Martin, X.: A growth model of inflation, tax evasion, and financial repression. J. Monet. Econ. 35, 275-301 (1995).

Shik, C.Y.: The personalist ethic and the market in Korea. Comp. Stud. Soc. Hist. 33, 106129 (1991).

Slemrod, J.: Cheating ourselves: The economics of tax evasion. J. Econ. Perspect. 21, 2548 (2007).

Slemrod, J., Yitzhaki, S.: The optimal size of a tax collection agency. Scand. J. Econ. 89, 183-192 (1987).

Slemrod, J., Yitzhaki, S.: Tax avoidance, evasion, and administration. In: Auerbach, A.J., Feldstein, M. (eds.) Handbook of Public Economics vol. 3, pp. 1423-1470. Elsevier, Amsterdam (2002).

Srinivasan, T.N.: Tax evasion: A model. J. Public Econ. 2, 339-346 (1973).

Tsakumis, G.T., Curatola, A.P., Porcano, T.M.: The relation between national cultural dimensions and tax evasion. J. Acc. Aud. Tax. 16, 131-147 (2007).

Varvarigos, D., Arsenis, P.: Corruption, fertility, and human capital. J. Econ. Behav. Organ. 109, 145-162 (2015).

Xin, K.R., Pearce, J.L.: Guanxi: Connections as substitutes for formal institutional support. Acad. Manage. J. 39, 1641-1658 (1996).

Yitzhaki, S.: Income tax evasion: A theoretical analysis. J. Public Econ. 3, 201-202 (1974). 